\title{
La formación de un mercado regional en el noreste del valle de México. De minas, ferrocarril y haciendas pulqueras (1850-1870)*
}

\begin{abstract}
Resumen
Este artículo tiene como objetivo develar los sucesos que hicieron posible la formación de un mercado regional en el noreste del valle central de México, mediante un estudio interpretativo de fuentes primarias y bibliografía especializada sobre los procesos que permitieron consolidar dicho mercado. Se analiza la inyección de capital de la Compañía de Minas de Real del Monte, la construcción del Ferrocarril Mexicano y el proceso de concentración de tierras y capital en las haciendas pulqueras, en el periodo de 1850 a 1870, cuando se sentaron las bases para un primer circuito agroindustrial y comercial que luego se convertiría en entidad federativa.
\end{abstract}

Palabras clave: México, cultivo, economía de mercado, minería, transporte ferroviario.

Referencias para citar este artículo: RAMÍREZ RODRÍGUEZ, Rodolfo (2017). "La formación de un mercado regional en el noreste del valle de México. De minas, ferrocarril y haciendas pulqueras (18501870)”. En Anuario de Historia Regional y de las Fronteras. 22 (1). pp. 17-48.

Rodolfo Ramírez Rodríguez: Candidato al Sistema Nacional de Investigadores del Consejo Nacional de Ciencia y Tecnología (CONACYT-México). Becario de estancia posdoctoral en la Facultad de Economía de la UNAM (área Historia Económica). Doctor y maestro en Historia por la Universidad Nacional Autónoma de México (UNAM). Licenciado en Historia por la Benemérita Universidad Autónoma de Puebla (BUAP). Correo electrónico: rudolf_rrr@yahoo.com.mx.

\footnotetext{
* El presente artículo es producto del proyecto de investigación Las inversiones privadas en el noreste del Valle de México y la comarca minera de Pachuca. Un acercamiento a la integración de una economía regional, 1850-1870, en el marco del Programa de Becas Posdoctorales de la Dirección General de Asuntos del Personal Académico, UNAM.
} 


\title{
The Creation of a Regional Market in the Northeastern Mexico Valley. Mines, Railways and Pulquera Ranches (1850-1870)
}

\begin{abstract}
Summary:
This article aims to unveil the events that made possible the formation of a regional market in the northeast of the central valley of Mexico, through an interpretative study of primary sources and specialized bibliography about the processes that allowed to consolidate the market. The capital injection of Mines Company Real del Monte are analyzed, the construction of Mexican railway and the process of land concentration and capital in the pulquera ranch in the period from 1850 to 1870, when the foundation was established for the first agro-industrial and commercial circuit, that later on would become a federal entity.
\end{abstract}

Keywords: Mexico, Crop, Market Economy, Mining, Rail Transport.

\section{A formação de um mercado regional no noroeste do vale do México. De minas, ferrovia e fazendas produtoras de pulque (1850-1870)}

\section{Resumo:}

Esse artigo tenta desvelar os eventos que tornaram possível a formação de um mercado regional no noroeste do vale central do México, mediante um estudo interpretativo de fontes primárias e bibliografia especializada sobre os processos que permitiram consolidar este mercado. Analiza-se a injeção de capital da Companhia de Minas de Real do Norte, a construção da Ferrovia Mexicana e o processo de concentração de terras e capital nas fazendas pulqueras no período de 1850 a 1870, quando as bases para um primeiro circuito agroindustrial e comercial se assentaram e se converteria em entidade federativa.

Palavras-chave: México, cultivo, economia de mercado, mineração, transporte ferroviário. 


\section{La construcción de un mercado interno}

El estudio del desarrollo regional, en la historia económica de México, abre interesantes caminos para comprender mejor la dinámica interna de ciertas regiones, para develar procesos productivos y engarzar actividades sociales y económicas que integran las características de un espacio en un determinado tiempo. En el caso de la región del noreste del valle central de México, que comprende la comarca minera de Pachuca-Real del Monte y la altiplanicie pulquera de los llanos de Apan, esta dinámica configuró una integración regional productiva al mediar el siglo XIX, que debido a abundancia de recursos e importancia geográfica en el comercio y transporte nacional, posibilitó la erección de un nuevo estado libre de la República mexicana.

Años atrás se había debatido sobre el proceso de desarrollo de la economía durante el primer siglo de vida independiente. Hasta hace unas décadas se creía que tras la independencia de España la economía se encontraba paralizada debido a la fuga de capitales peninsulares, a la contracción del mercado y a la caída de los principales productos y manufacturas del país, como la amonedación de plata, los textiles y los productos agrícolas y pecuarios ${ }^{1}$.

La importancia del desarrollo de las estructuras agrarias, de la recuperación de la actividad minera y de las industrias de la transformación (textil y tabaco), de la circulación, transporte y comercio de los bienes producidos y de la importancia del crédito y la banca en estos procesos, han sido estudiados atentamente por varios investigadores, quienes reconstruyen los procesos ocurridos del final de la época virreinal hasta las grandes transformaciones del siglo XIX ${ }^{2}$. No obstante, a pesar de esta diversidad de propuestas historiográficas, no se han desarrollado estudios comparativos o sistemáticos de historia económica regional ${ }^{3}$.

\footnotetext{
${ }^{1}$ Ceceña, José Luis. México en la órbita imperial. Las empresas transnacionales (México: El Caballito, 1975); Florescano, Enrique. Orígenes y desarrollo de la burguesía en América Latina, 1700-1955 (México: Nueva Imagen, 1985) y Coastworth, John H. Los orígenes del atraso. Nueve ensayos de historia económica de México, siglos XVIII y XIX (México: Alianza editorial, 1990).

${ }^{2}$ Cardoso, Ciro (coord.). México en el siglo XIX (1821-1910). Historia económica y de la estructura social (México: Nueva Imagen, 1994); Silva Riquer, Jorge; Grosso, Juan Carlos y Yuste, Carmen (comp.). Circuitos mercantiles y mercados en Latinoamérica, siglos XVIII y XIX (México. Universidad Nacional Autónoma de México [UNAM]. Instituto Mora, 1995); Ludlow, Leonor y Silva Riquer, Jorge (comp.). Los negocios y las ganancias de la Colonia al México independiente (México: UNAM-Instituto Mora, 1999); Romero Ibarra, María Eugenia (coord.). Las regiones en la Historia económica mexicana. Siglo XIX (México: Facultad de Economía/UNAM, 1999).

${ }^{3}$ En los últimos lustros se ha venido fortaleciendo una postura en donde se considera que la economía mexicana estaba en marcha, pero su lógica económica estaba en las regiones, teniendo una economía a menor escala, y hasta cierto punto con autonomía, pero que daba circulación a los bienes de consumo básicos que requería el país. Estos trabajos fueron coordinados por Silva Riquer, Jorge y López Martínez, Jesús. Mercado interno en México (México: Instituto Mora. El Colegio de Michoacán-El Colegio de MéxicoUNAM, 1998); Silva Riquer, Jorge (coord.). Los mercados regionales de México en los siglos XVIII y XIX (México: Conaculta-Instituto Mora, 2003). Una excepción es el trabajo de Cerutti, Mario. El siglo XIX en México. Cinco procesos regionales: Morelos, Monterrey, Yucatán, Jalisco y Puebla (México: Claves Latinoamericanas, 1985), donde enfatiza el diverso desarrollo económico en centros rectores regionales. Además vale la pena mencionar la colección de trece tomos temáticos (por sector o por periodo) de Semo, Enrique (coord.). Historia económica de México (México: UNAM-Océano, 2004 y 2006).
} 
Las investigaciones actuales revelan estudios de caso sobre la preeminencia de ciertas actividades productivas en los espacios de comercio regional en México, que permiten sugerir las bases de un mercado nacional a fines del siglo XIX, pero la cuestión regional es tratada levemente debido al enfoque del desarrollo de los sectores económicos ${ }^{4}$. De modo que existe un vacío de información en lo que respecta a las regiones económicas de segundo orden (el noroeste, las zonas costeras, el sur y las regiones satélites de este país), que no han sido estudiadas por la historia económica, ya sea por considerarse espacios deprimidos, que habían perdido su antiguo esplendor al término del periodo colonial, o por ser consideradas zonas de atraso por el predominio de los grupos indígenas. Todo lo anterior se conjuga en el territorio noreste del antiguo estado de México del cual se formaría la entidad federativa de Hidalgo. Pero a inicios del siglo XIX la región muestra decaimiento de la actividad minera, contracción del comercio de productos agrícolas y la dificultad de los medios de transporte, a más de una vasta población indígena.

La finalidad de este artículo es develar los procesos que en conjunto hicieron posible la formación de un mercado regional económico que, si bien es cierto dependiente del antiguo estado de México, fue creando las bases para una posterior autonomía política, la cual tuvo sus orígenes en el repunte de sus principales actividades productivas que tuvieron cabida en la zona del noreste del valle de México, justamente en los dos decenios entre 1850 y 1870 . Ahora bien, para comprender la dinámica socioeconómica de esa región es necesario explicar los hechos que, en orden de sucesión, impactaron en su proceso de recuperación: como la inyección de capital de la Compañía minera de Real del Monte, los planes de construcción de la primera línea férrea que uniría la ciudad de México con el puerto de Veracruz, cruzando los llanos de Apan y, finalmente, el proceso de concentración de tierras y capital en las haciendas pulqueras, luego del periodo de la Reforma que, sin duda, pusieron las bases para un primer circuito agroindustrial y comercial que se replicaría décadas después con la construcción de otros ferrocarriles en la región.

El término mercado tiene un doble significado, el coloquial se refiere al lugar de mercado, espacio físico donde se adquieren bienes; y el económico se refiere al sistema de mercado, que integra los distintos intercambios bajo el mecanismo ofertademanda-precios, de modo que la integración comercial o economía de mercado se basa en la interacción entre esas partes. Las mercancías a intercambiar son ilimitadas,

\footnotetext{
${ }^{4}$ Recientemente se publicaron dos obras monográficas de historia económica que han concebido a este periodo como una transición entre la recesión y la desintegración comercial al de una lenta recuperación e integración de un mercado nacional a fines del siglo XIX: Cárdenas Sánchez, Enrique. El largo curso de la economía mexicana de 1780 a nuestros días (México: Fondo de Cultura Económica [FCE]-El Colegio de México), pp. 141-187 y Kuntz, Sandra (coord.). Historia económica general de México: de la colonia a nuestros días (México: El Colegio de México-Secretaría de Economía, 2010), pp. 305-331. Sánchez Santiró, Ernest. "El desempeño de la economía mexicana 1820-1860, de la colonia al estado-nación”, en Kuntz, Sandra, Op Cit., p. 298, asevera que en las décadas de 1820 a 1850 se produjo una reestructuración de la economía, que le permitió reiniciar la senda de crecimiento en términos regionales. Sánchez Santiró, Ernest. "El desempeño de la economía mexicana tras la independencia, 1821-1870: nuevas evidencias e interpretaciones", en Llopis E. y Marichal C. (coords.). Latinoamérica y España 1800-1850. Un crecimiento económico nada excepcional (México: Marcial Pons-Instituto Mora, 2009), pp. 83-99.
} 
incluyendo tierras y trabajo ${ }^{5}$. El funcionamiento del mercado se adapta no solo a las mercancías sino también a cada elemento integrante del comercio (producción, almacenamiento, transporte, riesgo, crédito $)^{6}$. Es necesario reconocer la importancia de los estudios sobre el mercado interno pues estos permiten conocer los grados de integración nacional o regional ya que, como ha expresado el investigador Enrique Cárdenas: "El desarrollo regional dependía notablemente de su situación geográfica, de su dotación de recursos naturales y mercados urbanos locales, y del vigor de las fuerzas productivas y políticas de cada región"?.

Los investigadores de la historia económica han subrayado la importancia de la producción minera en la Nueva España, siendo determinante para la formación y desarrollo del mercado interno y para el proceso de mercantilización de las estructuras indígenas que impuso el dominio español, debido a su dinámica en la economía europea y en el mercado mundial ${ }^{8}$. El desarrollo de la minería en la Nueva España generó un proceso de circulación entre dos factores: la fuerza de trabajo y los artículos de agropecuarios y manufactureros en ciertas regiones, como en la comarca minera de Pachuca-Real del Monte. La minería fue el sector que permitió integrar el mercado interno de la región que luego se extendió a las unidades productivas agropecuarias, demandando productos mercantiles, tanto del espacio urbano como rural, formando así un circuito comercial, siendo la actividad minera la que impulsó la producción agrícola, ganadera y manufacturera ${ }^{9}$.

\section{Antecedentes de un mercado regional}

Para entender el proceso de esa economía regional se presenta una síntesis de lo acontecido tras la independencia política de España y hasta 1850, cuando surgiría un sistema de mercado, único y diferenciado, por sus producciones locales. ${ }^{10} \mathrm{~A}$ inicios del siglo XIX, incluso antes de la guerra de Independencia, la minería presentaba serios problemas estructurales: la necesidad de grandes inversiones requeridas para devolverle su anterior dinamismo, la falta de capital de trabajo, la escasez y carestía del crédito, así como la devaluación de los precios de metales preciosos y la carga fiscal que soportaban éstos ${ }^{11}$. En 1824 las minas de plata en el noreste del valle de

\footnotetext{
${ }_{5}^{5}$ Arcondo, Aníbal B. "La noción de mercado en economía y su utilización en Historia”, en Grosso, Juan Carlos y Silva Riquer, Jorge. Mercados e Historia (México: Instituto Mora, 1994), p. 20.

${ }^{6}$ Moreno Feliu, Paz. ¿El dinero? (Barcelona: Anthropos, 1991), p. 20.

${ }^{7}$ Cárdenas, El largo curso, p. 158. Para el autor la zona centro de México se caracteriza por dos factores: estar basada en una agricultura comercial destinada a los mercados urbanos, y contar primero con el ferrocarril a la ciudad de México, lo que originó fuera un mercado regional hegemónico para la capital, Ibíd., pp. 168-171.

${ }^{8}$ Sempat Assadourian, Carlos. "La organización económica espacial del sistema colonial”, en Silva y López, Op. Cit., p. 17.

${ }^{9}$ Ibid., pp. 22-29.

${ }^{10}$ El periodo comprendido entre 1824 a 1848 corresponde a la primera república federal de México, 1824 1835; a la república central, 1835-1846 y a la guerra contra los Estados Unidos, 1846-1848, caracterizado como una época de lucha de facciones y trastornos políticos, económicos y sociales.

${ }^{11}$ En 1801 se efectuó el cierre sus minas en Real del Monte. Ortiz Hernán, Sergio. Caminos y transportes en México. Una aproximación socioeconómica: fines de la Colonia y principios de la vida independientes (México, Secretaría de Comunicaciones y Transportes-FCE, 1994), p. 38.
} 
México se hallaban abandonadas (Pachuca, Real del Monte, Huasca, Omitlán y Mineral El Chico), y se mantenían en baja producción las minas de plomo y hierro de Cardonal, Zacualtipán y Zimapán.

Al inicio de la vida republicana de México empezó a llegar capital foráneo para las minas, procedente sobre todo de Inglaterra. Algunas de estas compañías inglesas fueron la de Unida Mexicana, la de Tlalpujahua, la de Bolaños y la Compañía de Aventureros de Real del Monte la cual recibió bajo convenio las minas y haciendas de beneficio del tercer conde de Regla, Manuel Romero de Terreros, además de arrendar haciendas agrícolas. Los ingleses se comprometieron a rehabilitar las minas y desaguarlas por medio de la introducción de máquinas de vapor, pagándole una renta anual al dueño, pudiendo explotar y refinar (beneficiar) los metales extraídos de otras minas. ${ }^{12}$ Luego de aportar $£ 352,000$ (15.9\% de la inversión minera extranjera en el país), la compañía extendió su control a las minas de plomo en Zimapán (a $120 \mathrm{~km}$ al noroeste de Real del Monte), a las minas de Morán en Real del Monte, y a minas en otros estados como Michoacán y Zacatecas. En 1825 planeó extender los trabajos a las minas abandonadas de Pachuca (a $6 \mathrm{~km}$ al suroeste), pero su explotación no se emprendió sino hasta los últimos años de vida de la empresa británica. ${ }^{13}$ La compañía emprendió varias mejoras en el camino México-Veracruz para poder transportar las máquinas de vapor que había importado desde Inglaterra. No obstante, en su curso perecieron animales de carga -a causa de una tormenta en Apan- y a arrieros, carreteros y obreros por el esfuerzo y a causa de fiebre amarilla. La compañía también construyó un camino carretero de $30 \mathrm{~km}$, que unía las minas con la hacienda de beneficio de Santa María Regla en Huasca. ${ }^{14}$

La compañía inglesa ejerció un dominio completo sobre la extracción y el beneficio en el distrito de Real del Monte-Pachuca. Mas, en el cuarto de siglo transcurrido, la explotación de los yacimientos de plata absorbió las inversiones de capitales hechas por la compañía (casi 16.2 millones de pesos) dando pocas ganancias, solo 11.1 millones de pesos plata. En 1849 la compañía enfrentó una grave crisis financiera que no pudo solventar (adeudaba \$3’747,285 al tercer conde de Regla y $\$ 670,000$ a los dueños de las minas de Morán) y, debido a que los accionistas ingleses no quisieron realizar nuevas inversiones, se dio a la venta a un grupo de inversionistas mexicanos (en tan solo $\$ 30,000$ cuando valía $\$ 5$ millones). ${ }^{15}$

\footnotetext{
${ }^{12}$ Randall, Robert W. Real del Monte: una empresa minera británica en México (México: FCE, 1977), pp. 49-50; Lyon, George Francis. Residencia en México, 1826, Diario de una gira con estancia en la República de México (México: FCE, 1984), pp. 219-222.

${ }^{13}$ Saavedra Silva, Elvira. Cambios provocados por la actividad minera-metalúrgica en la organización espacial de Pachuca-Real del Monte en el siglo XIX y sus impactos territoriales y socioeconómicos (tesis maestría en Geografía), FFYL/UNAM, 2006, cap. 4, subtema 4.1.

${ }^{14}$ Ortiz, Caminos y transportes, p. 155/Hidalgo entre selva y milpas... la neblina (México: SEP, 1992) pp. 147-148.

15 Randall, Real del Monte, p. 234. Otras compañías extranjeras que explotaban los yacimientos minerales en la región fueron la Compañia Unida Mexicana (con Lucas Alamán como presidente de la junta de administración local) controlando seis minas en el Mineral del El Chico, y la Compañía Anglo Mexicana que, además de explotar las minas de Guanajuato, tenía inversiones y explotaciones en Zimapán y Real del Monte. Ortiz Hernán, Sergio, Op Cit., pp. 150-151.
} 
Sobre al fracaso de las inversiones extranjeras en minas de la región se debe de tener en cuenta el relativo atraso técnico de la minería mexicana, el desconocimiento de los empresarios de las condiciones, costumbres y recursos del lugar, a las fallas administrativas, a los conflictos laborales y a los severos daños provocados durante el periodo que siguió a la independencia y hasta su recuperación a mediados del XIX. Las mejoras técnicas impulsadas por los extranjeros beneficiarían, sin embargo, a los subsecuentes empresarios. A pesar de considerarse a la Compañía inglesa como un fracaso financiero, esta permitió el rescate de las minas profundas de Real del Monte y la renovación de los espacios mineros, convirtiendo a ellas en un complejo funcional y bien equipado en tecnología que sería aprovechado por la compañía mexicana sucesora. Asimismo, fortaleció las relaciones económicas regionales del mercado interno, vinculando las actividades agrícolas, ganaderas y forestales de la región ${ }^{16}$.

En cuanto a las comunicaciones existentes en el noreste del valle de México, estas se encontraban en un estado de abandono completo, producto de la guerra de independencia. Durante ella, los Llanos de Apan fueron escenarios de batallas aisladas entre las fuerzas insurgentes y las tropas virreinales. Ahí se establecería el departamento del Norte, entre 1810-1816, que reunía fuerzas y fondos para la insurgencia (en los partidos de Otumba, Apan, Tulancingo y Zacatlán, este en el estado de Puebla) derivados de las contribuciones impuestas a las haciendas pulqueras ${ }^{17}$. El escenario en 1820, según escribió Julio Zárate en la gran obra México a través de los siglos, era:

Tanto como la minería, o tal vez más, había sufrido la agricultura del reino las duras e ineludibles consecuencias de la guerra: desaparecieron los ganados en muchas de las haciendas de labranza; en otras se carecía de los útiles más necesarios o sus oficinas habían caído en tierra; en las de caña de azúcar se hallaba destruida la maquinaria; y en las fincas productoras de pulque, esparcidas en la extensa zona de los Llanos, los magueyes se habían espigado, sin que se cuidase de hacer plantaciones de renuevos. Además, la decadencia en muchas de esas haciendas y la ruina de otras impedían a sus propietarios pagar los réditos de capitales que gravaban a casi todas $[\ldots]^{18}$.

Henry George Ward, comisionado de la Corona inglesa en 1823, al pasar por los llanos de Apan rumbo a la capital, escribió: "Otumba, como la mayoría de los pueblos pequeños que habíamos pasado, tenía todas las apariencias de haber sufrido" con la guerra de emancipación y adelante añade que "se requerirán muchos años de tranquilidad para borrar las huellas de ese periodo de sufrimiento"19. Esto se debía a que Otumba fue varias veces saqueado y quemado tanto por las fuerzas realistas como por el insurgente Francisco Osorno en la década anterior. Esta interrupción de la tranquilidad pública

\footnotetext{
${ }^{16}$ Ortiz Hernán, Sergio, Op. Cit., p. 154; Randall, Robert W., Op. Cit., p. 239; Saavedra, Op. Cit.

${ }^{17}$ Guedea, Virginia. La insurgencia en el Departamento del Norte. Los Llanos de Apan y la Sierra de Puebla, 1810-1816 (México: UNAM-Instituto Mora, 1996), pp. 99 y 128.

${ }^{18}$ Cursivas suyas. Riva Palacio, Vicente y Zárate, Julio. México a través de los siglos (La guerra de independencia- libro segundo), t. VI (México: Editorial Cumbre, 1984), p. 240.

${ }^{19}$ Ward, Henry George. México en 1827 (México: FCE, 1995), p. 438.
} 
tuvo el efecto de contraer el mercado, como se observa en la declinación de la arriería en el pueblo de Atotonilco El Grande, cercano a Real del Monte, que se dedicaba a abastecer de camarón, róbalo y otras especies de pescado seco a la ciudad de México, desde el Pueblo Viejo de Tampico. El intenso envío de productos marinos que desde allí se enviaba a Real del Monte y a San Luis Potosí acabó al mediar el siglo XIX. ${ }^{20}$

Asimismo, en relación a las unidades de producción agrícola de la región, antes de que se especializaran como haciendas pulqueras, las fincas rurales estaban dedicadas al maíz, la cebada y a la crianza de ganado porcino que era enviado a las fábricas de jabón y tocinerías de la ciudad de Puebla, a inicios del siglo XIX. De esta ciudad se enviaba a Apan, a su vez, piezas de mantas producidas en localidades como Huejotzingo. ${ }^{21}$ Este era un primigenio mercado regional que tuvo vigencia durante el periodo final de la colonia. Además, la concentración de tierras en los llanos de Apan, en manos de familias acaudaladas y con títulos nobiliarios, ${ }^{22}$ a fines del siglo XVIII, y el impulso de ser parte de la ruta comercial, que ligaba la capital con el puerto de Veracruz, sentó las bases para ser un centro de abasto de primer orden para la ciudad de México. ${ }^{23}$

Al iniciar el siglo XIX la producción de las fincas de los llanos de Apan, además del cultivo de cereales, se especializó en el pulque, el cual enviado en recuas de mulas a ciudades más alejadas como Puebla. ${ }^{24}$ Sin embargo, siempre diversificaban su producción para el autoconsumo o el intercambio. Al desarrollarse las minas en la región, la mano de obra que laboraba en ellas requirió de un continuo abastecimiento de pulque, como líquido que suplía al alimento y a la misma agua. El mercado que consumía la producción de los llanos de Apan era pues, en primera instancia, la comarca minera de Pachuca y Real del Monte y eventualmente la capital del país. ${ }^{25}$ Con el paso del tiempo el proceso de producción del pulque fue concentrado por familias criollas que eran dueñas de haciendas pulqueras y que tenían la mayoría de

\footnotetext{
${ }^{20}$ Ortiz Hernán, Sergio, Op Cit., p. 116; Peter Rees. Transportes y comercio entre México y Veracruz, 15191910 (México: SEP-Setentas, 1976), p. 168.

${ }^{21}$ Este autor afirma que: "Los datos e informaciones anteriores dan una idea de la relevancia del tráfico interno en el camino México-Veracruz y en otras rutas. Puede apreciarse que, al menos en las zonas pobladas del país, existía una producción para el mercado en una escala que muchas veces queda oculta si solo se atiende a las simplificaciones sobre la escasez de vías de comunicación ”, Ibíd., pp. 110-111.

${ }^{22}$ Entre las familias hispanas propietarias de las fincas pulqueras de Apan, que empezaron a establecer prácticas para una explotación más rentable de las plantaciones de maguey y de la venta del pulque en la capital, estaban los condes de Regla, Xala y Tepa, que aumentaron su poder a fines del Virreinato, Guedea, La insurgencia, p. 18. Ejemplo de ello fue el interés por el buen cultivo del maguey y la denuncia del mal comportamiento de los arrieros al adulterar el pulque con agua salobre inscritos en un libelo del hacendado José Mariano Sánchez Mora (tercer Conde de Peñasco). Memoria instructiva sobre el maguey o agave mexicano (México: Impresa por Tomás Uribe y Alcalde, 1837).

${ }^{23}$ Fue hasta el siglo XVIII el paso obligado de recuas de mulas e incluso ruta carretera, en los cuales transitaron los virreyes desde el puerto de Veracruz al centro de México, Rees, Transportes y comercio, pp. 59-63.

${ }^{24}$ Rees, Peter, Op Cit., p. 177. Se puede cotejar la información de AGN. Pulques, tomo I, ff. 197r-199v.

${ }^{25}$ Lau Jaiven, Ana y Sepúlveda, Ximena. Hidalgo, una historia compartida (México: Instituto Mora, 1994), p. 35. Como dato curioso se menciona que se había permitido a los mineros consumir el pulque dentro de las minas, pues con ello las enfermedades típicas de la profesión, como la "casca o madurez" (silicosis o neumoconiosis), habían desaparecido porque la bebida de maguey obraba como reparador y desinfectante de los síntomas del mal.
} 
las entonces 45 pulquerías existentes de la capital, gozando además de privilegios sociales y políticos. Esta cercanía geográfica propició una comunicación cercana, no solo entre los administradores y trabajadores de la región sino también entre los propietarios de las haciendas y los conductores del pulque ${ }^{26}$.

En agosto de 1824 se emitió la Ley Orgánica Provisional del estado de México que dispuso la creación del poder judicial al dividir el territorio (que se componía de los actuales estados de Guerrero, Morelos, Hidalgo y estado de México) en ochos distritos; a los distritos en partidos, y éstos a su vez en municipalidades. En cada uno de los distritos la autoridad se depositó un prefecto; los partidos en subprefectos y las municipalidades en los alcaldes. El antiguo estado de México tenía tres distritos que luego serían parte del estado de Hidalgo: el de Huejutla, Tula y Tulancingo. El distrito de Tulancingo, que corresponde a nuestra área de investigación, incluía los partidos de Apan, Otumba, Pachuca, Tulancingo y Zempoala.

Para 1825 Santiago Ortega, por orden del gobernador del estado de México, preparó un estudio del distrito de Tulancingo con el fin de incentivar mejoras en la industria en la región (según las investigaciones recabadas en informes previos de párrocos, empleados de gobierno y personas cultas del lugar). De esta manera se convierte en la primera persona en sugerir la creación de comisiones locales "científicas y economistas" en cada distrito del estado ${ }^{27}$. En los resultados del informe se menciona que "el oro y la plata se han llevado exclusivamente nuestra atención", por lo que no se han podido explotar otros minerales útiles como el hierro, el cobre y otros metales no preciosos.

En materia agrícola menciona que la región era muy fecunda en diversas producciones de frutas y leguminosas, que podrían ser mejor aprovechadas por personas con espíritu emprendedor para aumentar "los placeres del hombre y el producto de su industria"28. Resalta que el maguey de Apan y Zempoala era "el mejor que se conoce en la República"29; y que la cría de chivos y ovejas era de gran importancia en todo el distrito y la de cerdos en especial para Apan. Propone estimular la producción de la grana cochinilla, del añil, del lino y de la seda para textiles e incluso del papel de maguey. No obstante, el comercio al exterior era casi nulo pues casi todas sus producciones se consumían ahí, a excepción del pulque, que era "el único artículo que se saca fuera" del distrito ${ }^{30}$.

\footnotetext{
${ }^{26}$ Guedea, La insurgencia, pp. 18-19; Ladd, Doris. La nobleza mexicana en la época de la Independencia, 1780-1826 (México: FCE, 1984), pp. 63, 65-67; Kicza, John E. Empresarios coloniales. Familias y negocios en la ciudad de México desde los Borbones (México: FCE, 1986), p. 37. Un hacendado emparentado con familias distinguidas fue Ignacio Adalid y Gómez de Pedroso, quien luego apoyaría al movimiento de independencia y sería, junto con Josefa Adalid, el fundamento de una familia que ocuparía un destacado sitio entre los empresarios pulqueros del siglo XIX. Guedea, Virginia. "Ignacio Adalid, un equilibrista novohispano", en Rodríguez, Jaime E. (ed.). Mexico in the Age of Democratic Revolutions, 1750-1850 (Boulder \& London: Lynne Rienner Publishers, 1994), pp. 71-96.

${ }^{27}$ Ortega, Francisco. Ensayo de una memoria estadística del distrito de Tulancingo. Impreso de orden del Exmo. Sr. Gobernador del Estado (México: Imprenta de Alejandro Valdés, 1825), pp. 1 y 3-4.

${ }^{28}$ Ibid.

${ }^{29}$ Ibid.

${ }^{30}$ Ibid., pp. 6-8, 11-12 y 14.
} 
La formación de un mercado regional en el noreste del valle de México. De minas, ferrocarril...

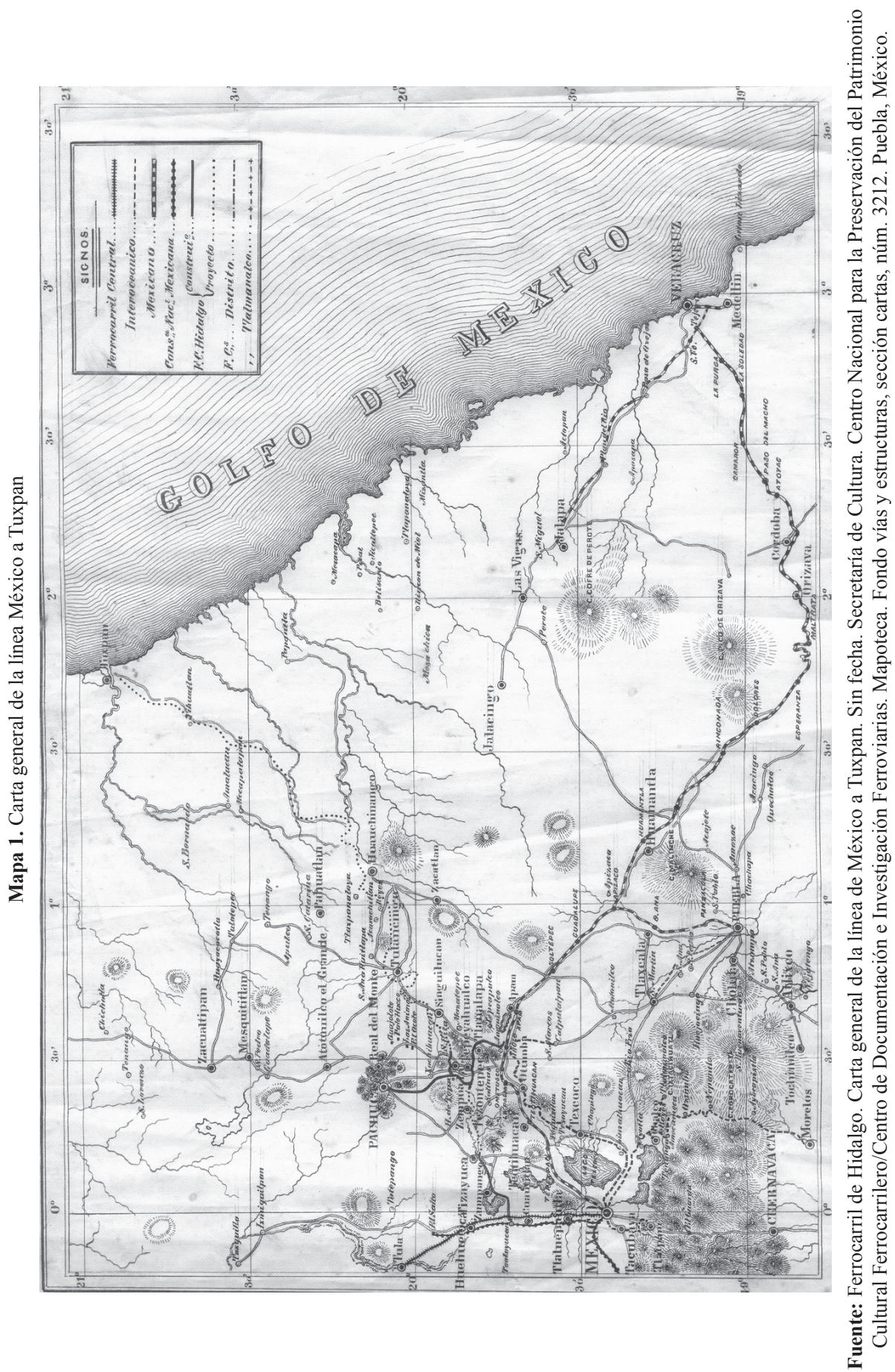


En cuanto a las actividades manufactureras menciona la existencia de dos molinos de harina en Tulancingo. No obstante, su producción no competía con las harinas de Puebla, de mejor calidad, que se utilizan para hacer pan. En cambio, los tejidos de algodón (que traen de la cercana sierra Madre) era uno de los ramos más importantes de la industria local del distrito, a pesar del poco consumo que experimentó luego de la caída de la minería ("cuyos operarios se vestían casi todos de mantas fabricadas en estos pueblos"31). Otros ramos eran: la loza de barro de Acaxochitlán, la fabricación de petates, tompeates y sombreros de palma y cordeles para las minas, además de todo género de jarcia con el hilo del ixtle de maguey. También se trabajaba la cordelería con las fibras del tallo de malva que crecía en tierras de Apan, todas estas eran manufacturas sencillas.

Durante la primera mitad del siglo XIX las haciendas pulqueras del noreste del valle de México funcionaron como las primeras empresas de la región orientadas hacia el mercado, siendo autosuficientes, consideradas como propiedades de primera clase por su valor, y resultando su primacía sobre los pueblos de la zona. De esta manera, se inició un proceso de creación de un sólido sistema de latifundios donde los hacendados aumentaron su control al constituirse sus propiedades "[...] en los puntos de referencia de una geografía agrícola desarticulada por la guerra y por los conflictos locales, proporcionando créditos e insumos productivos, reforzando cacicazgos regionales y garantizando la permanencia de los ciclos productivos y comerciales y la reproducción de una fuerza de trabajo crecientemente fijada a las haciendas"32.

A la par de la especialización productiva de las haciendas pulqueras como complejos regionales (unidades productivas características de una región que compartían el tipo productivo, histórico y social, asociadas a formas determinadas de reproducción, flujo y control de la fuerza de trabajo) la población rural mexicana, campesinos e indígenas, iba siendo marginada de la vida social y económica del país, conduciendo a una serie de litigios y revueltas de carácter agrario debido a la pérdida de su autonomía territorial, a causa de la presión hecha por la expansión de latifundios ${ }^{33}$.

\section{La bonanza minera de la Compañía de Real del Monte y Pachuca}

Tras el traspaso de poderes de la compañía inglesa a la primera administración mexicana de la nueva compañía, que coincide con el periodo 1850-1869, ésta tiene como características la elevada productividad y rentabilidad de la empresa, acompañada de un desarrollo sostenible favorecido por su organización basada en

\footnotetext{
${ }^{31}$ Había un registro de 265 talleres: Tulancingo contaba con 152 telares y 32 en el resto de la municipalidad; en Atotonilco el Grande eran 54; en Acaxochitlán, 5 telares; en Huasca 12 y en el partido de Pachuca 20. Era raro el pueblo "que no trabaja[ra] mantas, paños de rebozo, jerguetillas y cordoncillos de lana para mangas". Ibid., p. 11.

${ }^{32}$ García de León, Antonio. "Las grandes tendencias de la producción agraria”, en Semo, Enrique (coord.). Historia de la cuestión agraria mexicana, vol. I (México: Siglo XXI editores-CEHAM, 1998), p. 62.

33 Ibid., p. 77; Meyer, Jean. Problemas campesinos y revueltas agrarias (1821-1910) (México: SEPSetentas, 1973).
} 
redes familiares de empresarios y en capitales de familia, que hicieron de ella: "la compañía minera de capital nacional más importante de México y una de las más sobresalientes de la América Latina en ese largo periodo"34. En ese lapso su dominio en la actividad minera de la región fue total (en minas propias y ajenas), reinvirtiendo las ganancias obtenidas en la adquisición de equipos, bienes raíces, construcción y nuevas obras.

Con la opción de adquirir el establecimiento minero-metalúrgico, equipado y trabajado por mineros ingleses, prominentes hombres de negocios de la ciudad de México (socios de la compañía arrendataria de la Casa de Moneda de México y de la Compañía del Tabaco) entre los que destacaban Antonio Béistegui, su hijo Nicanor, Edwin Mackintosh, Manuel Bringas, Manuel y Joaquín Escandón, constituyeron una sociedad por acciones con la denominación de Sociedad Aviadora de minas de Pachuca y Real del Monte, una empresa mayoritariamente mexicana ${ }^{35}$.

El $1^{\circ}$ de junio de 1849 la Compañía de Aventureros en las Minas Real del Monte vendió y traspasó todas las acciones y derechos de las minas a los directivos mencionados de las empresas del Tabaco y de la Casa de Moneda, por la cantidad de $\$ 30,000$, más gastos extras. En la junta general de accionistas, de ese mismo día, se nombraron como miembros de la junta directiva de la nueva empresa a Nicanor Béistegui, Manuel Escandón y Alejandro Bellangé ${ }^{36}$. Su organización financiera refleja un tipo de estructura compleja, en comparación con el resto de las empresas mexicanas de la época, antes de la irradiación de las sociedades anónimas. Puede interpretarse que, al contar con el proceso de extracción de plata y de acuñación de

\footnotetext{
${ }^{34}$ Herrera Canales, Inés. "Empresa minera y región en México. La Compañía de Minas de Real del Monte y Pachuca (1824-1906)", en Siglo XIX. Cuadernos de historia, vol. IV, núm. 8, México, 1979, pp. 103123; Ruiz de la Barrera, Rocío. "La empresa de minas de Real del Monte (1849-1906). Medio siglo de explotación minera: ¿Casualidad o desarrollo estratégico?”, en Marichal, Carlos y Cerutti, Mario (comp.). Historia de las grandes empresas en México, 1850-1930 (México: Universidad Autónoma de Nuevo León/ FCE, 1997), pp. 291-316.

${ }^{35}$ Meyer, Rosa María. "Los Béistegui, especuladores y mineros, 1830-1869”, en Cardoso, Ciro (coord.). Formación y desarrollo de la burguesía en México. Siglo XIX (México: Siglo XXI editores, 1987), pp. 108-139. Meyer explica el funcionamiento de la empresa como aviadora: "La Compañía Real del Monte estaba dedicada al avío de las minas situadas en la región de Pachuca y su labor era financiar a quien denunciara una mina abandonada pero que, una vez estando en posesión de ella, no contaba con los recursos económicos para trabajarla. Por lo general, en los contratos de avío se establecía que una mina se dividía en 24 barras (o acciones) de las cuales 18 pertenecían a la compañía aviadora -mientras ésta permaneciera en funciones-y las 6 restantes, que eran bastante aviadas, quedaban en propiedad del dueño o los dueños de la mina. En un principio la compañía invertía capital en el laborío de la mina hasta que ésta empezaba a producir; posteriormente lo primero que se hacía era reintegrar a la compañía el capital invertido; una vez hecho esto, las ganancias se repartían entre aviados y aviadores de acuerdo al número de barras que tuvieran. La compañía se reservaba el derecho de abandonar el avío cuando lo creyera conveniente o si la mina no resultaba productiva", Ibid., p. 127.

${ }^{36}$ Ibíd., pp. 126-127. Meyer describe el tipo de compañía que se gestó: "En la escritura que se realizó para la formación de la compañía de la Empresa de Minas de Real del Monte, se estableció que ésta se dividía en 205 acciones distribuidas de la siguiente manera: Nicanor Béistegui 73 3/4, Manuel Escandón 53 3/4, Joaquín Escandón 45, Miguel Bringas 17 1/2, Juan H. Buchan 10 y Palamade de la Roche 5". En esta misma escritura se señala que la junta general de accionistas tendría la representación radical de la empresa siendo mayoría por acciones y no por personas.
} 
la moneda se podía monopolizar la producción de plata en la capital, constituyendo un excelente instrumento para especular con la recurrente deuda pública del gobierno mexicano en el siglo XIX ${ }^{37}$. Esta organización del capital se modificó en los primeros meses de 1850 debido a la separación de dos socios. La división de las acciones se modificó también, predominando la representación del Monopolio del Tabaco (con $49 \%$ ), quedando la Casa de Moneda con una minoría (un 2\% de acciones), por lo que la empresa tabacalera asumió el control de la gestión del capital en $1851^{38}$.

Al principio la compañía minera no obtuvo ganancias y sí endeudó a la Compañía del Tabaco (1850-1851). Empero, en 1852, con la bonanza de la mina El Rosario, en Pachuca, Nicanor Béistegui planteó la autonomía de la compañía para emitir acciones $\mathrm{y}$, en caso de obtener ganancias, repartir los dividendos y poder enajenar las acciones; las compañías arrendatarias dejaron de ser accionistas para dar lugar a representaciones individuales. En mayo de 1852 se constituyó ante notario la Compañía de Minas de Real del Monte, Sociedad Anónima ${ }^{39}$.

Las ganancias obtenidas entre 1852 y 1860 atrajeron a hombres de negocios, “[ ... conformándose una amplia red de accionistas integradas por otras más pequeñas entrelazadas por un común denominador de parentesco". Para el éxito de la empresa, los accionistas de la compañía no se centraban únicamente en la minería sino que estaban vinculados a propiedades urbanas y rurales, al comercio, las finanzas, la industria, los servicios, los cargos públicos y la actividad profesional. La primera junta directiva, constituida entre otros por Manuel Escandón y Nicanor Béistegui, se mantuvo por casi dos décadas (1849-1868), siendo este último quien ejerció el cargo de la toma de decisiones pues mantuvo casi la mitad de las acciones totales en el periodo (47\% en 1867$)^{40}$. La dirección de la empresa estuvo siempre en las mismas manos hasta la República Restaurada, cuando se modificó el contexto político y social que afectó a la configuración de la empresa.

Por otra parte, el potencial de los yacimientos de Pachuca facilitó que la administración mexicana aceptara el riesgo de invertir en el distrito con un fuerte capital en 1852. El

\footnotetext{
${ }^{37}$ Ruiz de la Barrera, Rocío. La empresa de Minas del Real del Monte (1849-1906) (tesis de doctoral), Centro de Estudios Históricos/El Colegio de México, 1995, pp. 71-78.

${ }^{38}$ Ibíd., pp. 298-299. Debido a la separación de Mackintosh y Bellangé y a la adquisición de 5 acciones por Buchan, la organización de capital cambió en 1850 de la siguiente forma: J. H. Buchan 10 acciones (5\% del total); Casa de Moneda 5 acciones (2\%); J. A. Bésitegui, 45 acciones (22\%); J. Escandón 45 acciones (22\%) y el estanco del Tabaco 100 acciones (49\%); cf. Ruiz de la Barrera, Rocío. "Acciones y accionistas de una empresa minera del siglo XIX", en Universidad de México, Revista de la UNAM, núm. 544, México, mayo de 1996, p. 47.

${ }^{39}$ Así se reorganizó otra vez la estructura de capital a inicios de 1852: Nincanor Béstegui con 73.75 de acciones (36\%); Manuel Bringas con 17.5 acciones (8.5\%); Buchan con 10 acciones (5\%); Joaquín Escandón con 45 acciones (22\%); Manuel Escandón con 53.75 acciones (26\%) y Palamade de la Roche con 5 acciones $(2.5 \%)$, Ibid.

${ }^{40}$ Se presupone que Nicanor Béistegui fungió como presidente de la Junta directiva desde 1849 y hasta marzo de 1868, cuando se retiró del cargo, pero sin enajenar su participación en la empresa. La administración de ella quedó en manos de accionistas con menor experiencia sin el cargo de director. Ruiz, La empresa de minas, pp. 131-132.
} 
auge incomparable de la mina de El Rosario, comenzado en 1853 y hasta 1863 , y la de Guautimotzin, con ganancias de 1869 a 1871 (la cual llegó a ser el yacimiento más importante de todo México), se consideró como una consecuencia del esfuerzo de inversionistas privados que aprovecharon las mejoras técnicas, realizadas en las décadas pasadas, y que aprovecharon las circunstancias del momento ${ }^{41}$.

En cuanto a las razones del éxito de la compañía se deben -además de la principal bonanza de producción minera que vivió Real del Monte y Pachuca entre las décadas de 1850 y 1860 - a que las operaciones de explotación y beneficio fueron desarrolladas bajo un plan estratégico, tanto técnico como administrativo, con un fuerte apoyo financiero durante los primeros cuatro años que se vio fortalecido por las buenas decisiones de la Junta directiva, sobresaliendo Nicanor Béistegui como director, quien no adquirió cargas financieras innecesarias ni contrajo deudas que arriesgasen el capital. Además del trabajo operativo del director inglés John H. Buchan, quien se propuso reducir los costos fijos (los pagos a los dueños de las minas, los gastos generales y del desagüe), mediante el beneficio de minerales pobres de plata pero abundantes a menor profundidad, le permitieron hacer frente a los gastos de la exploración y aumentar los de explotación ${ }^{42}$.

Por otro lado, el desarrollo del grupo empresarial -del que formaba parte Manuel Escandón-absorbió varias ramas productivas básicas como la minería; la integración y monopolización de los medios de comunicación en los caminos, transportes y puertos; la relación con el mercado del tabaco; la imposición de regímenes laborales ventajosos; e incluso el contrabando durante periodos de prohibición de mercancías. El modo de organización de sus empresas se basaba en los vínculos de parentesco dentro de la esfera pública y del gobierno que beneficiaron sus relaciones estratégicas económicas en el interior y exterior del país. De este modo logró acumular el capital necesario para proyectar la obra del ferrocarril que, como se ve más adelante, prometía modernizar la vida económica de México y "abrir las posibilidades para intensificar y diversificar las fuentes de acumulación, sin romper las actividades tradicionales"43.

La racionalidad económica de la compañía Aviadora le permitió no solo efectuar su proceso productivo, sino la comercialización y el transporte del producto de plata. Para ello acrecentó las propiedades de su complejo minero e integró su actividad con los sectores agrícola y comercial, abasteciéndose de materias básicas e insumos y controlando la exportación y venta de plata, e incluso recurrió a mecanismos de coerción para conseguir recursos forestales y mano de obra. Para efectuar esta integración firmó contratos con productores, comerciantes y transportistas, así como con los gobiernos federal y estatal. Las actividades de extracción de minas y de beneficio las realizó en los distritos de Pachuca, Real del Monte, Omitlán, El

\footnotetext{
${ }^{41}$ Ruiz de la Barrera, Rocío, Op. Cit., p. 311.

${ }^{42}$ Burkart, Joseph. Memoria sobre la explotación de minas en los distritos de Pachuca y Real del Monte (facsímil de 1861, Pachuca: Universidad Autónoma de Hidalgo, 1989), pp. 52-113; Ruiz de la Barrera, Rocío, Op. Cit., pp. 111 y 118.

${ }^{43}$ Urías H., Margarita. "Manuel Escandón: de las diligencias al ferrocarril” en Cardoso, Formación, p. 27; infra p. 32.
} 
Chico y Huasca, pero su influencia económica llegaba a los de Zimapán, Tulancingo, Ixmiquilpan y $\mathrm{Apan}^{44}$.

Las áreas de suministro agrícola, en una primera época, eran en las llanuras de Atotonilco el Grande, Tulancingo y los llanos de San Javier (al sur de Pachuca) y se recurría para los recursos forestales al Chico, Real del Monte y la sierra de Tulancingo. De las rutas, el camino a la ciudad de México se transitaba por San Javier y Tizayuca; el de Veracruz se dirigía por Zempoala hasta Apan, uniéndose a la ruta principal; para Tampico partía por Real del Monte, Omitlán y Atotonilco hacia la Huasteca; para el Valle del Mezquital se iba desde Pachuca o El Chico hacia Actopan e Ixmiquilpan, para seguir al norte hasta la región minera de Zimapán ${ }^{45}$.

La actividad básica de la empresa era la extracción de minerales que se efectuaba en las minas de Pachuca, Real del Monte y Atotonilco El Chico y su beneficio en las haciendas de Omitlán y en San Antonio, San Miguel y Santa María Regla en Huasca. Entre 1863 y 1875 la compañía trabajó 105 minas entre propias y aviadas, siendo solo tres o cuatro rentables. Como empresa aviadora dio servicio a pequeños mineros para la molienda y beneficio de mineral, alquiler de tierras, transporte, etc., lo que le permitió acrecentar sus ganancias que llegaron a representar casi la mitad el producto anual de la compañía, luego de su producción de plata. Para 1867 la empresa poseía 36 minas propias y dominaba el resto por medio del avío. En ese periodo la compañía tuvo diez haciendas: 4 dedicadas a la molienda del mineral (Aviadero, Carmen, Guerrero y Peñafiel) y el resto a la labor de beneficio (Regla, San Miguel, San Antonio, Sánchez, Velasco y Loreto $)^{46}$.

Los establecimientos de la compañía tenían un carácter diverso que aseguraban el abastecimiento, cuidado y almacenaje de los productos en minas y haciendas. Estos eran caballerizas ubicadas en Pachuca, Agua Bendita, Santa Águeda y Velasco; haciendas agrícolas o forestales que producían maíz, cebada, leña, madera y carbón en La Venta, Ocotillos, San José Istula, Tepezala, Zembo, rancho Guajolote, Ocotengo y Cuyamaloya; almacenes de depósito, como el general de San Cayetano, el cual surtía de velas, sogas, cables y mulas a las minas, además de otros menores en Pachuca y Real del Monte; salinas en Tepopoxtla, a la orilla del lago de Texcoco, una mina de carbón y de hierro, una fábrica de sulfato de cobre, depósitos de leña, fábricas de ladrillos, de "apartado de metales" y de toneles. Además de "maestranzas" de carpintería, carrocería y herrería con equipamiento de fraguas, hornos de fundición y maquinarias, a más de predios urbanos en Pachuca. Esas propiedades constituían el patrimonio de la compañía, que mantenía comunicación

\footnotetext{
${ }^{44}$ Herrera Canales, Inés. "La racionalidad económica de la empresa minera Real del Monte y Pachuca, 1849-1875", en Anuario II (Organización de la producción y relaciones de trabajo S. XIX) (Jalapa: Centro de Investigaciones Históricas, Instituto de Investigaciones Humanísticas/Universidad Veracruzana, 1979), pp. 208-223.

${ }^{45}$ Ortega Morel, Javier. Minería y ferrocarriles: el caso de Pachuca-Real del Monte, 1870-1906, (tesis de maestría), FFYL/UNAM, 2002, pp. 31-32.

${ }^{46}$ Calderón, Francisco. "El Palacio del rey de Oros", en Historia Moderna de México, vol. II (México: Editorial Hermes, 1955), pp. 121-124. Herrera, "La racionalidad económica", pp. 210-212.
} 
con cada una ellas por medio de un sistema de caminos, construidos y mantenidos con los recursos de la empresa o con la recaudación de impuestos locales a productos como el pulque ${ }^{47}$.

En la década de 1850 se efectuó una absorción de bienes útiles para la empresa: se compraron acciones de minas aviadas que luego entraron en bonanza como El Rosario, Jacal, Guadalupe, Guatimotzin y Dolores; se adquirieron haciendas forestales y agrícolas como El Zoquital, Ocotengo, San Antonio Tula y San José del Marqués y los ranchos de San José, San Francisco y Don Tomás; y haciendas de beneficio Guadalupe y El Carmen ${ }^{48}$.

En materia de contratos, la compañía logró el abastecimiento de materias importadas para su proceso productivo, además de la comercialización y transporte interno de la plata por medio de vínculos con agentes comerciales y con casas comisionistas, quienes se encargaron de importar y distribuir lo requerido, así como de enviar la plata a los puertos y exportarla al extranjero. En algunas ocasiones los comerciantes eran agentes y accionistas de la compañía y viceversa. Asimismo recurrió al estado y a la federación para conseguir permisos excepcionales, exenciones tributarias e incluso protección armada. En un informe sobre una vista que realizó Mariano Riva Palacio, gobernador del estado de México, a la Compañía de Real del Monte, en 1850, la junta directiva le sugirió que la solución a su necesidad de trabajadores para sus minas y haciendas era la creación de un presidio. Ante esa petición el gobernador accedió al permiso de contratar a los reos sentenciados de los distritos de Tulancingo, México, Tula, Huejutla, Sultepec y Toluca, estableciéndose el presidio a cargo de la compañía (el primer contrato fue 1850 y se renovó varias veces hasta 1875). Asimismo, el gobierno estatal autorizó la creación de una fuerza armada para vigilar a los reos, pero que fue utilizada para el control de los trabajadores ${ }^{49}$.

La compañía también obtuvo permisos para exportar la plata en barras, en compensación por los préstamos otorgados por la empresa a los gobiernos nacionales, considerando los empréstitos como adelantos de los derechos de "acuñación, circulación y salida" de plata en ciertos periodos. En febrero de 1862 se le concedió la exención del pago del 3\% de derecho de plata por un periodo de 10 años, decretando el presidente Benito Juárez le exención de todos los demás derechos que causaren en los distritos de Pachuca, Real del Monte, Huasca y Omitlán y del pago de contribuciones a la Federación y del estado de México ${ }^{50}$.

\footnotetext{
${ }^{47}$ Herrera Canales, Inés. "La racionalidad económica de la empresa minera Real de Monte y Pachuca, 18491875", en Anuario II... Op Cit., p. 211.

${ }^{48}$ Ibid., pp. 212 y 213.

${ }^{49}$ Ejemplo de comercializadoras de plata fueron la Casa comisionista Garruste, Labadie y Compañía, de la cual fue accionista Manuel Escandón. Al transformarse en la Casa Teodoro Labadie y Compañía, en 1860 y hasta 1863, exportó plata con permiso especial del gobierno. El principal abastecedor de azogue fue la agencia de Barron y Forbes, socios de la empresa minera. Arístides Soubervielle, dueño de una línea de carros entre México y Veracruz, e introductor de mercancías importadas, era un socio menor de la compañía. Ibíd., pp. 215-217.

${ }^{50}$ Entre 1860 y 1863 la Compañía obtuvo once permisos de exportación de plata, que en total ascendía a 8,558 barras, sin contar las enviadas al a Casa de Moneda de México. Ibíd., pp. 217-218.
} 

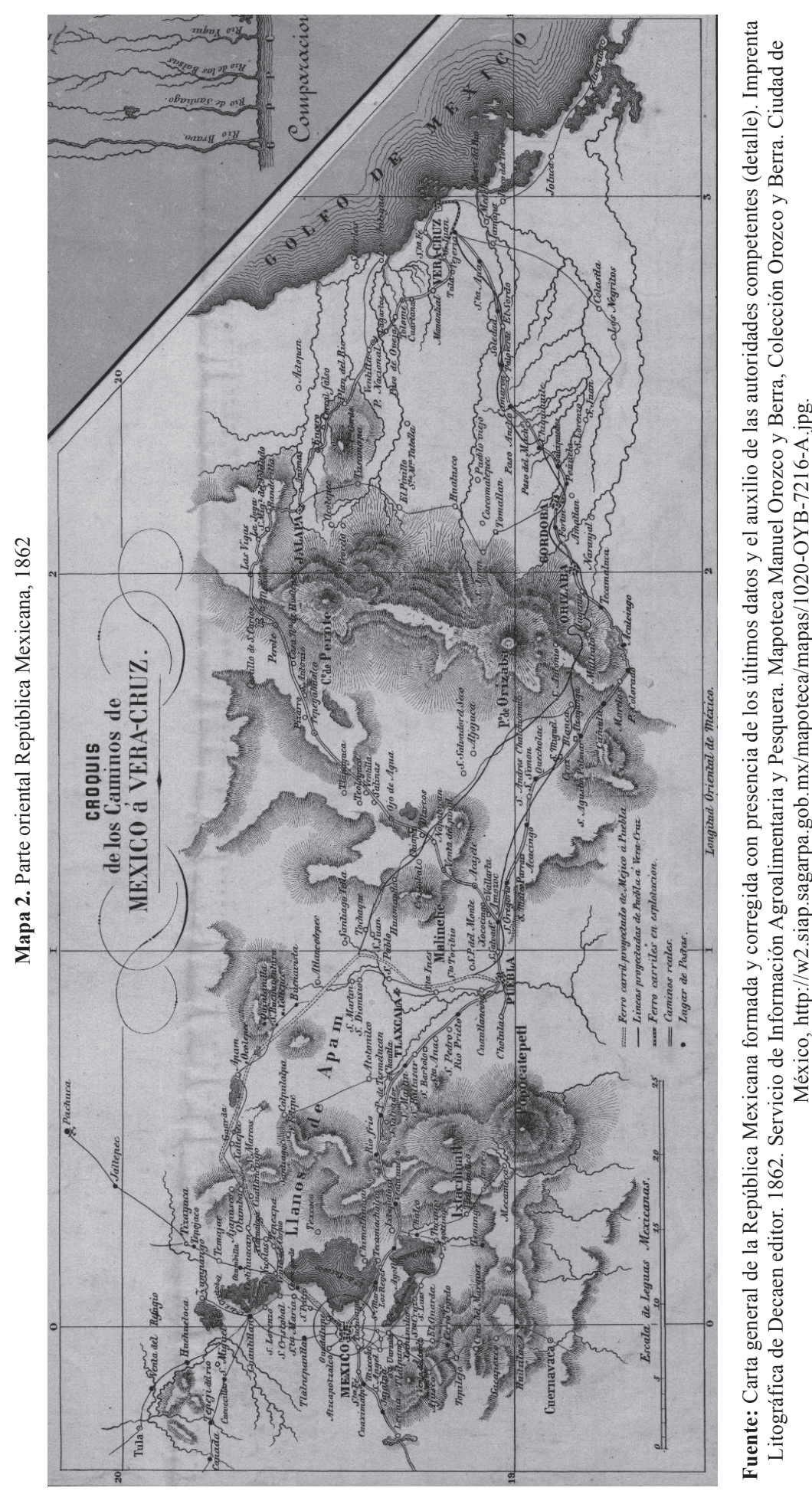
Durante los años de bonanza de las minas fue posible la prosperidad de la empresa. ${ }^{51}$ Hasta 1868 esta situación se mantuvo inalterable teniendo una situación financiera exitosa pero, entre 1868 y 1872, surgieron problemas de operación ocasionados por el agotamiento de los yacimientos y la depreciación de la plata en el mercado mundial. La crisis económica de la compañía se agudizó entre 1873 y 1875, cuando se registraron los movimientos laborales más importantes ante la reducción de salarios, suspendiéndose los trabajos en Real del Monte, lo que produjo desempleo y la compañía comenzó a registrar pérdidas valuadas hasta en $\$ 1^{\prime} 000,000^{52}$.

\section{La llegada del ferrocarril y el inicio del auge pulquero}

El transporte decimonónico dependía de las condiciones naturales y de las posibilidades prácticas de la arriería hasta la introducción del ferrocarril. La escasez de comunicaciones era uno de los principales impedimentos para extender las relaciones de mercado (la producción de productos agropecuarios y su intercambio a mayores distancias que su entorno inmediato). No obstante, la parte central del país, que contaba históricamente con mayor población, fue la mejor comunicada, además de que en ella tenían lugar las principales actividades productivas. La problemática de los caminos y transportes, sin embargo, continuaron como obstáculos para el desarrollo económico y social de México. Los altos fletes y la poca capacidad de carga impedían el transporte en masa ${ }^{53}$.

El estado de las comunicaciones y la tecnología del transporte se caracterizaron, por lo menos hasta los años de 1870, por la ausencia casi absoluta de mejoras netas. Los medios de transporte habían experimentado una involución, desde el fin de la época colonial y hasta la restauración de la República en 1867. Esto se debía al deterioro causado por el paso del tiempo, a la falta de mantenimiento de las obras, al debilitamiento del gobierno virreinal, a las insurrecciones y a la precaria fortaleza del nuevo estado-nación, que contribuyeron a la casi nula inversión en las comunicaciones y a la consecuente destrucción de gran parte de la red de rutas terrestres ${ }^{54}$.

Muchos de los caminos carreteros (sin mencionar los de herradura o de tracción animal) tendían a desaparecer por la falta de mantenimiento, que los volvía

\footnotetext{
${ }_{51}$ En la compañía había 40 familias que detentaban $60 \%$ de las acciones patrimoniales. Veinte años después de haber comenzado sus operaciones le pertenecían más del 75\% de las barras aviadas de las minas a la compañía y la mayor parte restante estaban distribuidas entre los accionistas de la compañía y los empleados de alta jerarquía. Ruiz de la Barrera, Rocío, Op. Cit., pp. 301-304. Herrera Canales, Inés; Velasco Ávila, Cuauhtémoc y Flores Clair, Eduardo. Etnia y clase, los trabajadores ingleses de la Compañia Real del Monte y Pachuca, 1824-1906 (Seminario de condiciones de trabajo y situación de las clases trabajadoras en México, siglo XIX) (México: Departamento de Investigaciones Históricas/Instituto Nacional de Antropología e Historia, 1981), p. 32.

${ }^{52}$ Herrera Canales, Inés; Velasco Ávila, Cuauhtémoc y Flores Clair, Eduardo, Op Cit., p. 23. Saavedra Silva, Elvira, Op Cit., apartado 4.2.1.2.

${ }^{53}$ Ortiz Hernán, Sergio, Op Cit., p. 186.

54 Riguzzi, Paolo. "Los caminos del atraso: tecnología, instituciones e inversión en los ferrocarriles mexicanos, 1850-1900", en Kuntz Ficker, Sandra y Riguzzi, Paolo. Ferrocarriles y vida económica en México (1850-1950). Del surgimiento tardío al decaimiento precoz (México: El Colegio Mexiquense Ferrocarriles Nacionales de México- Universidad Autónoma Metropolitana/Xochimilco, 1996), pp. 40-41.
} 
intransitables en la temporada de lluvias, reduciéndolas a veredas intransitables hasta para las bestias de carga. Según una estadística del Ministerio de Fomento de 1854, en el Departamento de México (territorio que hoy ocupan los estados de Hidalgo, México y Morelos) los tramos carreteros que tenían tramos intransitables eran: el de México-Apan, México-Pachuca y México-Tierra Caliente, según los informes de los distritos de Apan, Temalatla, Temascalapa y Mazatepec ${ }^{55}$.

El cambio fundamental en la tecnología de los transportes, representado por la introducción de los ferrocarriles, se convirtió en un ultimátum para la inmutabilidad de las rutas camineras anteriores, propiciando nuevos circuitos y trazos. El perfeccionamiento del transporte fue una parte integral de cualquier inversión futura, sobre todo en las inversiones extranjeras. Las concesiones en materia de ferrocarril comenzaron con la otorgada por el gobierno mexicano a Francisco Arrillaga, en 1837, cuando se intentó realizar una línea férrea que comunicara la ciudad de México y el puerto de Veracruz, a través de los llanos de Apan. Sin embargo, el optimismo, la subestimación de los costos, la dificultad en la construcción y la sobrestimación del volumen de comercio que podrían suscitarse, impidieron el buen término de este proyecto $^{56}$.

A pesar de que la minería y algunas manufacturas sostenían la economía de México, al mediar el siglo XIX, el deterioro de caminos, la inseguridad en ellos y la carestía del transporte de recuas habían reducido a su mínima expresión el comercio interregional del país. ${ }^{57}$ A mediados del siglo XIX existían tres caminos proyectados para el ferrocarril de la capital del país a su principal puerto: la ruta de Arrillaga, que dejaba a un lado las ciudades pobladas; la de Antonio Escandón, a través de Córdoba y Orizaba, y la de Jalapa, en donde tenía intereses particulares el general Antonio López de Santa Anna, por hallarse en la ruta algunas de sus haciendas. En palabras del historiador John Gresham Chapman, la construcción del ferrocarril "reflejaba los intereses económicos de una oligarquía orientada hacia las actividades mercantiles"

No obstante, estaba claro que la innovación ferroviaria no solo facilitaría el comercio a la larga distancia, avivando la economía nacional, sino también la movilidad en el mercado interno. Con mucho esfuerzo se fue creando el plan del Ferrocarril Mexicano, entre 1837 y 1855 . En ese año otra concesión fue otorgada a la compañía de los Hermanos Mosso (Miguel y Leandro) donde se imponía a la compañía el uso del tramo ya terminado de Veracruz-San Juan y que la línea pasara por la ciudad de Puebla y los llanos de Apan para la capital. ${ }^{59}$ Pero fue hasta 1857 cuando el gobierno mexicano

\footnotetext{
${ }^{55}$ Ibíd., infra pp. 44-45, Riguzzi cita los Anales de Fomento, tomo I, del Ministerio de Fomento de México, 1854.

${ }^{56}$ Rees Peter, Op Cit., pp. 98, 103, 107 y 109.

${ }^{57}$ González, Luis, et al [Florescano, Enrique; Lanzagorta, María del Rosario; Flores Caballero, Romeo; Herrera Canales, Inés y Bazant, Jan]. La economía mexicana en la época de Juárez (México: Secretaría de Industria y Comercio, 1972), p. 18.

${ }^{58}$ Chapman, John Gresham. La construcción del ferrocarril mexicano (1837-1880) (México: SEP, 1975), pp. 38-41.

${ }^{59}$ Cuando los hermanos Mosso recibieron la concesión, en 1855, se agregaron dos miembros más a la compañía: José Antonio Suárez y Manuel Payno. No obstante, la Compañía Hnos. Mosso tuvo varias
} 
traspasó la concesión a Antonio Escandón. Manuel y Antonio Escandón, hijos de un comerciante español avecindado en Orizaba, fueron empresarios conspicuos durante la primera mitad del siglo XIX. El mayor, Antonio, debió su fortuna a la primera línea de diligencias México-Veracruz fundada, según él, en $1830 .{ }^{60}$ Por otra parte, los hermanos Escandón mantuvieron una neutralidad política durante los gobiernos de la década de 1850 .

En la primera concesión del Ferrocarril otorgada por el presidente Ignacio Comonfort a Antonio Escandón, en 1856, la compañía estaba integrada por comerciantes establecidos en la ruta México-Veracruz, ligados al comercio con Europa, como Labadie y Lelog con firmas en los puertos de Veracruz y Tampico. Era presidente de la compañía Gregorio Mier y Terán y vicepresidente el hacendado y comerciante Mariano Riva Palacio. Con estas prerrogativas la obligación de la Compañía se redujo a saldar los gastos de la anterior empresa de los hermanos Mosso y al gobierno por los tramos de ferrocarril construidos entre Veracruz y San Juan y de México a la villa de Guadalupe, ${ }^{61}$ mas no hubo acuerdo ulterior en este sentido, por lo que el 31 de agosto de 1857, siendo presidente Comonfort y Manuel Siliceo ministro de Fomento, Manuel Escandón recibió una nueva concesión de ferrocarril, reformando el privilegio de los hermanos Mosso, tal vez influyendo en ello Manuel Payno que era ministro de Hacienda ${ }^{62}$.

La amistad entre Antonio Escandón y el ministro Manuel Payno quedó evidenciada durante la inauguración del ferrocarril de $5 \mathrm{~km}$ entre México y la villa de Guadalupe, el 4 de julio de 1857. Antonio Escandón a nombre de la Compañía invitó al presidente Comonfort, a los ministros y a las personas notables de la ciudad de México. Durante la inauguración, Alejandro Arango Escandón, representante de la compañía, Manuel Payno y Comonfort pronunciaron discursos. Un editorial aparecido en un diario de la ciudad de México publicaba, en relación a este hecho, que el “[...] espíritu de empresa, todavía no desarrollado en México, se vería estimulado por el éxito del ferrocarril”; sin embargo, se debía considerar este primer paso como un experimento dirigido a introducir en México la idea del ferrocarril y no como un triunfo en sí mismo ${ }^{63}$.

En un escrito propagandístico sobre el ferrocarril del año 1858, Breve exposición al público sobre el negocio del camino de fierro entre Veracruz y México, Manuel Escandón explica que multitud:

dificultades económicas y cuando el gobierno le solicito la fianza de la concesión, en 1856, no pudo pagarla, por lo que decidió vender la concesión a Antonio Escandón. Chapman, Jhon Gresham, Op. Cit., pp. 47 y 51.

${ }^{60}$ Escandón, Manuel. Breve exposición al público sobre el negocio del camino de fierro entre Veracruz y México (México: Imprenta de Andrade y Escalante, 1858), pp. 14-15; Chapman, Jhon Gresham, Op. Cit, p. 53.

${ }^{61}$ Urías Hermosillo, Margarita. "Manuel Escandón de las Diligencias al Ferrocarril. 1833-1862” en Cardoso, Ciro... Op. Cit., pp. 32 y 48.

${ }^{62}$ Chapman, Jhon Gresham, Op. Cit., p. 60. Manuel Escandón menciona que había invertido \$2’000,000 en el ferrocarril.

${ }^{63}$ Bossero, Luis. "Editorial", El Estandarte Nacional, 5 de julio de 1857, p. 1. Chapman, Jhon Gresham, Op. Cit., p. 57. 
[...] de productos que hoy no se explotan, o sé explotan solamente en la reducida escala que permite el consumo interior, adquirirán un prodigioso desarrollo, pudiendo exportarse sin el menor recargo que hoy causan los fletes, y se les abriría la entrada a los mercados extranjeros [...] La honesta ocupación y la utilidad que su producción rindiese no solo mejoraría la condición de nuestro pueblo, sino que traería de fuera gente sosegada, laboriosa, dada a las artes de la paz, tal como conviene al verdadero adelanto y prosperidad de la República. ${ }^{64}$

El efecto sería mayor consumo y demanda en el mercado de productos agrícolas e industriales, o por lo menos así lo pensaba el mayor de los hermanos Escandón. En 1858 él consideraba que se podía financiar la construcción del ferrocarril con su propio capital, unido al subsidio del gobierno y con la suscripción de acciones por parte de capitalistas mexicanos. De esta forma se fomentaría el interés público en la construcción de las vías férreas; sin embargo, no tuvo el respaldo esperado por inversionistas mexicanos al fracasar la venta de las acciones en nuestro país, por lo que tuvo que recurrir a integrar una empresa con inversores extranjeros dirigiéndose a la Gran Bretaña donde formó la Agencia del Ferrocarril Mexicano en $1861^{65}$.

De 1857 a 1862, entre la Guerra civil y la intervención francesa, la empresa ferrocarrilera de los Escandón tuvo serias dificultades en la construcción a causa de los disturbios políticos; pero su relación con los gobiernos en turno fue de menos a más, primero especialmente con el de Juárez. Manuel Escandón tenía una influencia considerable en su gobierno y su apoyo continuó hasta la época de intervención. Pero con su muerte, la familia Escandón cambió de orientación política pues Antonio fue miembro de la Comisión de notables que ofreció la corona de México a Maximiliano, en octubre de 1863, a quién presentó el proyecto y buscó un contratista en Londres para formar una sociedad anónima, cuando era un hecho la implantación del Segundo Imperio ${ }^{66}$.

Debido a que los capitales de financiamiento seguían siendo muy exiguos, Antonio Escandón formó la Compañía Ferroviaria Imperial en Londres, en 1864 (con la cesión de la franquicia de Manuel Escandón). Con ella se abrió el camino de la inversión europea en este tipo de empresas, debido al fracaso de reunir capital en México. No obstante, la inversión británica directa no fue mayoritaria ni tampoco regiría el Consejo de administración, por lo que Antonio mantuvo un papel predominante, en

\footnotetext{
${ }^{64}$ Escandón, Manuel, Op Cit., p. 5.

${ }^{65}$ Los miembros más importantes de la Agencia fueron Manuel Escandón y Eustaquio Barrón, suegro de Antonio. Antonio Escandón viajó a Estados Unidos para contratar al ingeniero Andrew Talcott para que hicieran un levantamiento topográfico de las rutas con el fin de decidir cuál era la más conveniente $\mathrm{y}$, a pesar de que se le presentó el informe preliminar del ingeniero Pascual Almazán de la ruta por Jalapa, solo se verificó el levantamiento de la ruta por Orizaba, siendo obvio que la decisión de los hermanos Escandón ya estaba tomada, Chapman, La construcción, pp. 64-65, 67, 69. Manuel Escandón argumentó en 1861 (cuando se reanudaba la construcción de la línea férrea) que la región de Orizaba-Córdoba tenía una mayor densidad de población y más actividad económica. Asimismo dejó fuera de la ruta del ferrocarril a la ciudad de Puebla, lo que originó inconformidades. Escandón, Manuel. Segunda exposición al público sobre el negocio del camino de fierro entre México y Veracruz (México: Imprenta de Ignacio Cumplido, 1861), pp. 8-9; Chapman, Jhon Gresham, Op. Cit., pp. 59 y 64.

${ }^{66}$ Chapman, Jhon Gresham, Op Cit., pp. 74-79 y 86-87.
} 
el que se supone que el título de empresa extranjera lo haya motivado para guardar apariencias y hallar protección diplomática en caso de afectaciones durante esos $\operatorname{años}^{67}$.

Con la restauración de la república, en 1867, Juárez expidió un decreto donde perdonaba a la Compañía la cancelación de la concesión por su vinculación al Segundo Imperio y por la cesión particular que hizo Antonio Escandón en Londres, al considerar la importancia del ferrocarril como de utilidad pública, por lo que se le otorgó una nueva concesión en donde se reconocieron los beneficios que tuvo durante el Imperio y se fijaron plazos para la conclusión del tramo México a Puebla (para 1868) y Apizaco a Paso del Macho (al finalizar 1871); además de determinarse las tarifas máximas para el transporte de carga y pasajeros. Por lo que la Compañía promovida por los Escandón salió venturosa de este difícil trance; pues los gobiernos liberales, tanto de 1861 como de 1867, se mostraron dispuestos y accesibles con la empresa, lo que demuestra el gran valor que otorgaban a la utilidad del ferrocarril ${ }^{68}$.

Entre 1866 y 1868 se dieron importantes avances en la construcción del Ferrocarril Mexicano, uniendo a la capital del país con los valles de Otumba, Apan y Tlaxcala, a pesar de que, al principio, la Compañía tuvo resistencia por llevar su trazo por las estribaciones altas de los llanos de Apan, mas luego cedió ante los intereses de los propietarios particulares y de los ayuntamientos locales. ${ }^{69}$ Hasta 1865 la producción pulquera de los llanos de Apan llegaba a la garita de Peralvillo en la ciudad de México, su principal mercado, gracias al tráfico que hacían de él los arrieros, siendo el principal problema de su comercialización la rápida fermentación y su frágil emulsión. La carga, regulada aún en arrobas, la conducían en cueros a lomo de mula y por tal conducción se les pagaba un flete cercano a un real por arroba, que oscilaba según la distancia recorrida. En cuanto a la forma de transporte del pulque, idéntica desde inicios del siglo XIX, se decía que los arrieros realizaban discretamente una compostura con agua salobre del pulque que habían tomado para su consumo o que habían reglado o vendido en el camino ${ }^{70}$.

\footnotetext{
${ }^{67}$ Ibid., pp. 99-103.

${ }^{68}$ Ibid., pp. 129-130. No obstante el principal crítico de esta política de conciliación fue Manuel Payno quien rechazó la concesión por considerarla caduca. Payno, Manuel. Memoria sobre el ferrocarril de México a Veracruz (México: Imprenta de Nabor Chávez, 1868), 152 p. (en Payno, Manuel. Obras completas, vol. XX, México: Conaculta, 2007).

${ }^{69}$ Rees, Transportes y comercio, pp. 113-115 y 119/AGN. Fomento-Ferrocarriles, t. 9, exp. 138 y t. 10, exp. 149.

70 "Los arrieros salen regularmente de las Haciendas [de los Llanos de Apan], desde las 8 hasta las 10 de la mañana, y caminan sin parar hasta las dos de la siguiente madrugada en que llegan a los pueblos de Tulpetlac, San Cristóbal, Santa Clara, Venta de Cerro Gordo y Zalcoalco; en cualquiera de éstos hacen paradas, que ellos llaman repechar, y en estos parajes es por lo regular donde le echan agua al pulque, que nunca sabe puro, más que en San Martín y en las mismas Haciendas donde se produce, para reponer así el que legítimamente les falta o el que se han bebido o regalado o vendido. El agua que le echan es por lo regular de los pozos, muy salobre y es muy raro el arriero que no hace esta picardía y entregue el pulque tan puro como lo recibió”. Cursivas en original, loc. cit. de 1837 en Payno, Manuel. Memoria sobre el maguey mexicano y sus diversos productos (México: Imprenta de A. Boix, 1864), p. 57.
} 
Pero esta forma de transporte fue reemplazada por otra más fácil y segura, el ferrocarril, pues con este medio habría vagones especiales para el embarque de barriles, lo cual suponía una mayor seguridad en el trayecto; el traslado se realizaría con mayor rapidez y seguridad, además abría un nuevo camino a los productores de pulque, pues se suprimirían a los intermediarios, teniendo contacto directo con los compradores de la bebida para las pulquerías y fondas de la capital. Esto lo advirtió Manuel Payno hacia 1864 manifestando que, con el ferrocarril, el comercio llegaría a lugares que hasta entonces resultaban inalcanzables, trascendiendo en la expansión del mercado:

\begin{abstract}
El establecimiento del Camino de fierro, cuya línea está trazada precisamente por los llanos de Apam (sic), va á cambiar completamente el sistema establecido por tantos años. En dos horas, los pulques serán conducidos de las haciendas á las ciudades de Puebla y México, y de allí partirán entonces los atajos de mulas para caminar otras ocho ó diez horas y llevar los pulques en un nuevo radio de 25 leguas, a puntos donde hoy no se puede conducir [...] Establecido el camino de fierro, parece indudable que duplicarán los productos de las Haciendas, por consiguiente el valor de todos esos terrenos. Las habitaciones de las Haciendas, hoy solitarias y casi abandonadas, serán otros tantos lugares de recreo y de buen gusto, a la vez que el pulque se tomará puro, será más agradable y muy provechoso á la salud ${ }^{71}$.
\end{abstract}

En 1865, las localidades de Otumba y Apan habían ofrecido a la compañía del Ferrocarril Mexicano tierra gratuita para el establecimiento de una estación, que justamente atravesara los dominios de varias haciendas agrícolas y pulqueras. El F. C. mexicano unió la estación de Buenavista de la capital con los llanos de Apan en 1866 (aunque el servicio de carga y pasajeros fue interrumpido en diciembre de 1866), con Apizaco en 1867, con Puebla en 1869 y, finalmente, en 1874 con Veracruz ${ }^{72}$. Los principales puntos de embarque de pulque del F. C. eran las estaciones de Apan (del futuro estado de Hidalgo), Ometusco y Otumba en el de México, Soltepec y Apizaco en Tlaxcala, donde se esperaba una considerable baja de costes por el flete de carga del ferrocarril. Con el reinicio de actividades del ferrocarril, a mediados de 1868 , se presentó entonces una disminución en las ventas de pulque en el estado de México. El gobierno de ese estado trató de exigir a la Compañía que le informara de la cantidad de pulque cargada en los otros estados por donde pasaba, demanda motivada por los problemas que tenían los productores de pulque, ante la apertura a la competencia de ese ramo que propiciaba el ferrocarril, mostrando cierto desequilibrio en la economía regional. Seguramente esta demanda, la cual no fue considerada, se debía a los hacendados vecinos de la zona de los llanos de $\operatorname{Apan}^{73}$.

En una economía agraria cerrada y fragmentada, como lo eran vastas zonas geográficas del país, incluido el antiguo estado de México, con prevalencia de actividades rutinarias y tradicionales y mercados consuetudinarios, el abaratamiento de los productos agrícolas causado por la aparición del ferrocarril en la zona, entre

\footnotetext{
${ }^{71}$ Payno, Manuel, Op. Cit., p. 58.

${ }^{72}$ Chapman, Jhon Gresham, Op. Cit., pp. 19, 126, 136 y 140.

${ }^{73}$ Ibid., pp. 135-136.
} 
1866 y 1873, podía representar una amenaza concreta para determinados grupos de productores, como fue el caso para el recién creado estado de Hidalgo (en 1869), cuyas autoridades afirmarían en 1872: “iLíbrenos Dios de considerar nunca como un mal la presencia de vías férreas en nuestra patria! Pero estas siempre introducen algunas perturbaciones en las industrias que suplen". La baja de precio de los granos era, en este sentido, un aparente bien pero en realidad era un positivo mal ${ }^{74}$. Por otra parte, como el historiador Paolo Riguzzi apunta, había una racionalidad económica en el rechazo a la inversión de construcción de ferrocarriles por su baja rentabilidad, lo que generó la ausencia de relaciones entre ferrocarriles y mercados de capital locales, pero tal vez en el fondo existía un inquietud sobre el tipo de conformación de un mercado interno, regional y nacional. En palabras de este autor: "Desde cierto punto de vista, en México había riquezas pero no capitales, o por lo menos no existía identidad entre los dos elementos, debido a que las oportunidades de inversión doméstica eran muy escasas y no existían bancos o intermediarios financieros" 75 .

La lenta integración del país implicó cambios bruscos que no serían fácilmente asimilados en muchas regiones, incluyendo a la región noreste del estado de México, declinando en algunos casos los cultivos tradicionales y de autoconsumo. El panorama agrícola era muy variado según las regiones (dependiendo las formas de tenencia, las modalidades de explotación, la concentración demográfica, su origen étnico, el tipo de producto y su demanda, la cercanía de los mercados) ${ }^{76}$. Sin embargo, la aplicación de nuevas técnicas, unida a la expansión de la propiedad privada, fue aprovechada para activar algunos de los productos más representativos del país para ser comercializados a gran escala, como ocurrió con las haciendas pulqueras que captaron más fuerza de trabajo e inversión para ser más productivas, unido al proceso de expansión territorial ${ }^{77}$.

La introducción del ferrocarril fue uno de los factores que más alteró las formas tradicionales de transporte y comercialización del pulque en la región. Al comienzo no pareció traer muchos beneficios para las haciendas, ya que su producción agrícola fue relegada por los altos costos en los fletes para los pueblos de Hidalgo, en comparación con los que colindaban con la cuenca del valle de México. Sin embargo, con el paso del tiempo, ese impacto negativo fue atenuado por la importancia gradual que iba tomando la demanda del pulque, lo que propició un incremento en la plantación

\footnotetext{
${ }^{74}$ Cosío Villegas, Daniel (coord.). Historia moderna de México. La República Restaurada. La vida económica (México: Hermes, 1955), pp. 57-58. en Riguzzi, “Los caminos”, infra p. 52.

75 Riguzzi, Paolo. "Los caminos del atraso: tecnología, instituciones e inversión en los ferrocarriles mexicanos, 1850-1900”, en Kuntz... Op Cit., p. 59.

${ }^{76}$ Nickel, Herbert J., Morfología social de la hacienda mexicana (México: F.C.E., 1996), pp. 105 y 150; Ortiz, Op Cit., pp. 60 y 66.

${ }^{77}$ Un ejemplo de ello se encuentra en la queja de un productor de pulque llamado Manuel A. Campero en 1857 quien pide la intervención de la justicia para su rancho pulquero de Tepatepec, en el municipio de Axapusco (en la región de los llanos de Apan), pues a pesar de que pagaba impuestos a su propiedad, los pobladores vecinos usaban la tierra y tenían la idea de que eran tierras públicas que se convirtieron de forma ilegal en propiedad privada, en Dabbs, Jack Autrey. The Mariano Riva Palacio Archives. A Guide, University of Texas Library (Independent Mexico in Documents: Independence, Empire, and Republic), vol. II (México: The institute of Latin American Studies-The University of Texas/Editorial Jus, 1968), p. 534.
} 
de magueyeras en los llanos de Apan y un aumento proporcional en la producción pulquera que intensificó su mercantilización, haciendo que el mercado regional de los Llanos quedara plenamente integrado a la influencia económica de la ciudad de México $^{78}$.

\section{Como colofón, el asunto político}

La búsqueda por la autonomía en el territorio del noreste del estado de México, que luego sería conocido como estado de Hidalgo, tenía su principal origen en la necesidad de que el poder coincidiera con la autoridad: "Es decir, el gobierno debía estar determinado en su estructura y funcionamiento por las fuerzas sociales y económicas subyacentes"; en otras palabras, el interés de una élite regional que fuese presentada como voluntad popular para obtener ese fin ${ }^{79}$.

Un hijo de propietarios agricultores, Manuel Fernando Soto, al triunfo de la Revolución de Ayutla y antes de la instalación del Congreso Constituyente de 1857, argumentó la necesidad de la creación del estado de Iturbide (conformado primigeniamente por los distritos de la Huasteca), siendo conveniente para el nuevo estado integrar a los distritos de Huejutla, Tulancingo y Tula, pues representaba una ventaja explotar con mayor provecho la economía de dichos distritos:

El discurso de Soto, y las acciones tomadas por él, en tanto prefecto del distrito de Tulancingo, y por su sucesor, mostraban que los fundamentos del poder político del estado de México, representado por las autoridades que residían en Toluca y por las que estas designaban para ocupar las prefecturas de los distritos, no coincidían con la disposición y funcionamiento de las fuerzas económicas y sociales subyacentes en estas jurisdicciones, cuyos intereses coincidían mejor con los de una posible nueva entidad que con las de aquella a la que pertenecían ${ }^{80}$.

Ante las dificultades que representaba conformar una nueva entidad con distritos de otros estados del país (el caso de las Huastecas) el proyecto fue desechado. Pero una nueva oportunidad se presentó cuando se decretó la nueva constitución del estado de México, en 1861, en la que se estableció que se organizaría su jurisdicción a partir de distritos. Por lo que vecinos de esa región noreste, residentes en la ciudad de México, integrantes de una elite empresarial de dicha región, designaron una comisión para que se presentara una iniciativa para la creación de un nuevo estado con el nombre de Hidalgo. Esto motivó a que el núcleo de autonomistas pasara de la Huasteca a Tulancingo y Tula. Este proyecto se fortaleció cuando Benito Juárez dividió al estado de México en tres distritos militares, a mediados de 1862. Al término de la guerra de la intervención francesa, los pueblos del segundo distrito militar promovieron la erección del nuevo estado. Así, se presentaron los argumentos a favor de la creación

\footnotetext{
${ }^{78}$ Rees, Peter, Op Cit., pp. 177-178; Lau Jaiven, Ana y Sepúlveda, Ximena, Op Cit., p. 225.

${ }^{79}$ Lugo Pérez, David. Hidalgo. Documentos para la historia de su creación (Pachuca: Instituto Hidalguense de Desarrollo Cultural e Investigaciones Sociales, 1994), pp. 12 y 13.

${ }^{80}$ Ibid., p. 15.
} 
en el Expediente sobre división del estado de México y formación de uno nuevo con el nombre de Hidalgo. Por lo que, los congresistas del país, después de avalarlo, tomaron la decisión del decreto de erección el 16 de enero de $1869^{81}$.

Con la conformación del estado de Hidalgo en la República mexicana se logró un suceso que parecía poco probable: reunir en una entidad federativa a un conjunto de regiones que parecían inconexas (social, cultural y económica diferentes), separándolas del entonces aún extenso estado de México. Pero no solo era una cuestión política sino, más allá de su origen de distrito militar durante la Intervención francesa, este era un espacio estratégico para el comercio con las regiones de la costa del Golfo de México y del Altiplano central del país. Sus límites con los estados de Puebla, Veracruz, San Luis Potosí, Querétaro, Tlaxcala y con el reducido estado de México, podía ser considerado como el establecimiento de una región estratégica para el comercio interno del país, concentrado decisiones de un territorio que distaba algunas jornadas de la capital.

Ante estas consideraciones y tomando en cuenta que la región del altiplano central de México debe su desarrollo económico a la bonanza de la minería y a la agricultura, se considera necesario hacer énfasis en la organización económica y al desarrollo de este mercado interno, en el periodo de 1850 a 1870, lo que sin duda fue impulsado por decisiones de orden social y política de algunas personalidades destacadas en los negocios de la zona. El auge que inició la minería, como actividad dominante en la región, constituyó el primer detonante que permitió que este espacio renaciera (Pachuca, Real del Monte y Mineral del Chico). Al mismo tiempo, el crecimiento de la inversión y la producción pulquera se relacionó muy pronto con el proyecto de construcción del ferrocarril, que merece atención aparte, pues fue el factor principal en la incorporación del noreste de estado de México en un mercado regional relacionado con la capital del país, pues esta era el principal destino de la bebida embriagante durante el siglo XIX.

Como se ha visto, primero se presentó un repunte en la actividad minera de la región, con la compañía británica, retomada por una sociedad empresarial mexicana que gozó del beneficio de las utilidades y aportó inversiones en la modernización de la producción de plata. Ante este éxito, unos accionistas de la Compañía Aviadora de Pachuca y Real del Monte, los hermanos Escandón, apostaron por la incorporación de la moderna vía de transporte que representaba el ferrocarril, por lo que inyectaron capitales surgidos de la minería regional para consolidar el proyecto del F. C. México-Veracruz. Por otra parte, durante los años de estudio, la producción pulquera adquirió un rasgo preponderante en la actividad agrícola de la zona, en dirección a la especialización del cultivo y de la conformación de un mercado regional con la ciudad de México. Debido a la importancia que tuvieron tanto la actividad minera como la producción pulquera en esta región, esto posibilitó la instauración de un medio efectivo en el transporte de mercancías, lo que posteriormente dio origen a una primera etapa de integración de México a un mercado nacional.

\footnotetext{
${ }^{81}$ Expediente sobre la división del Estado de México y formación de uno nuevo con el nombre de Hidalgo, México, s. p. i, 1875, pp. 17-18.
} 
Ante estos procesos centrales para la historia de esta región de intercambio: la intensificación del movimiento comercial, en particular, y la activación de la economía, en general, se tiene como resultado el beneficio a una población económicamente activa en la minería y la agricultura, ante la ausencia de fuertes capitales invertidos en sectores de mayor envergadura. Lo anterior finalmente derivó de las implicaciones de todos estos mecanismos: tráfico comercial, concentración productiva, formación de empresarios regionales y el primer intento de articulación de un mercado en la zona que tuvo el binomio de minería de plata y de agroindustria del pulque, siendo ello un promotor de la instauración del ferrocarril. Solo falta relacionar que estos eventos de orden económico tuvieron el impacto en la formación del estado de Hidalgo, atribuyéndole una dimensión social y política al proceso, fundándose en una homogeneidad de intereses ya sean reales o virtuales (habitantes, costumbres, intereses, extensión territorial, riqueza de la propiedad, importancia del comercio y de los productos de los impuestos), que sostuvieran una nueva identidad, o si más bien fue motivado por intereses particulares y económicos promotores de una nueva entidad federativa. En este artículo se propone a pensar en la segunda opción, ya que la importancia adquirida con minas, haciendas pulqueras y ferrocarril diferenciaron la zona que sería el estado de Hidalgo, pues, con la importancia económica y política conseguido por hombres de empresa, pudo darse el siguiente paso de pensar en una autonomía que organizará el vasto territorio del noreste del antiguo valle de México, que comprende el altiplano pulquero y la comarca minera.

\section{Fuentes}

\section{Fuentes primarias}

\section{Archivos}

Archivo General de la Nación México (AGN) Fondo Real Hacienda. Serie Pulques, tomo I, ff. 197r-199v.

AGN Fondo Comunicaciones y Obras Públicas. Serie Ferrocarriles, tomo IX, exp. 138 y tomo X, exp. 149 .

\section{Publicaciones impresas}

Anales de Fomento, t. I. México: Ministerio de Fomento, 1854.

Expediente sobre la división del Estado de México y formación de uno nuevo con el nombre de Hidalgo. México: s. p. i, 1875.

\section{Libros}

Escandón, Manuel. Breve exposición al público sobre el negocio del camino de fierro entre Veracruz y México. México: Imprenta de Andrade y Escalante, 1858. 
La formación de un mercado regional en el noreste del valle de México. De minas, ferrocarril...

Escandón, Manuel. Segunda exposición al público sobre el negocio del camino de fierro entre México y Veracruz. México: Imprenta de Ignacio Cumplido, 1861.

Ortega, Francisco. Ensayo de una memoria estadística del distrito de Tulancingo. Impreso de orden del Exmo. Sr. Gobernador del Estado. México: Imprenta de Alejandro Valdés, 1825, 14 pp. + cuadros.

Sánchez Mora, José Mariano [José Ramo Zeschan Noamira pseud.]. Memoria instructiva sobre el maguey o agave mexicano. México: Impreso por Tomás Uribe y Alcalde, 1837, 40 pp. cuadros.

\section{Fuentes secundarias}

\section{Libros}

Burkart, Joseph. Memoria sobre la explotación de minas en los distritos de Pachuca y Real del Monte (facsímil de la $1^{a}$ edición en español de 1861). Pachuca, Universidad Autónoma de Hidalgo, 1989.

Cárdenas Sánchez, Enrique. El largo curso de la economía mexicana de 1780 a nuestros días. México: Fondo de Cultura Económica-El Colegio de México, 2015.

Cardoso, Ciro (coord.). México en el siglo XIX (1821-1910). Historia económica y de la estructura social. México: Nueva Imagen, 1994.

Ceceña, José Luis. México en la órbita imperial. Las empresas transnacionales. México: El Caballito, 1975.

Cerutti, Mario. El siglo XIX en México. Cinco procesos regionales: Morelos, Monterrey, Yucatán, Jalisco y Puebla. México: Claves Latinoamericanas, 1985.

Chapman, John Gresham. La construcción del ferrocarril mexicano (1837-1880). México: SEP-Setentas, 1975.

Coastworth, John H. Los orígenes del atraso. Nueve ensayos de historia económica de México, siglos XVIII y XIX. México: Alianza editorial, 1990.

Cosío Villegas, Daniel (coord.). Historia moderna de México. La República Restaurada. La vida económica. México: Hermes, 1955.

Dabbs, Jack Autrey. The Mariano Riva Palacio Archives. A Guide (University of Texas Library-Independent Mexico in Documents: Independence, Empire, and Republic), vol. II. México: The institute of Latin American Studies-The University of Texas/ Editorial Jus, 1968.

Florescano, Enrique. Orígenes y desarrollo de la burguesía en América Latina, 17001955. México: Nueva Imagen, 1985. 
González, Luis, et al. La economía mexicana en la época de Juárez. México: Secretaría de Industria y Comercio, 1972.

Guedea, Virginia. La insurgencia en el Departamento del Norte. Los Llanos de Apan y la Sierra de Puebla, 1810-1816. México: UNAM-Instituto de Investigaciones Dr. José María Luis Mora, 1996.

Herrera Canales, Inés; Velasco Ávila, Cuauhtémoc y Flores Clair, Eduardo. Etnia y clase, los trabajadores ingleses de la Compañía Real del Monte y Pachuca, 18241906 (Seminario de condiciones de trabajo y situación de las clases trabajadoras en México, siglo XIX). México: Departamento de Investigaciones Históricas/INAH, 1981 (Cuaderno de Trabajo núm. 38).

Hidalgo entre selva y milpas... la neblina. Monografía estatal, México: SEP, 1992.

Kicza, John E. Empresarios coloniales. Familias y negocios en la ciudad de México desde los Borbones. México: Fondo de Cultura Económica, 1986.

Kuntz, Sandra (coord.). Historia económica general de México: de la colonia a nuestros días. México: El Colegio de México-Secretaría de Economía, 2010.

Ladd, Doris. La nobleza mexicana en la época de la Independencia, 1780-1826. México: Fondo de Cultura Económica, 1984.

Lau Jaiven, Ana y Sepúlveda, Ximena. Hidalgo, una historia compartida. México: Instituto de Investigaciones Dr. José María Luis Mora, 1994.

Ludlow, Leonor y Silva Riquer, Jorge (comp.). Los negocios y las ganancias de la Colonia al México independiente. México: UNAM-Instituto de Investigaciones Dr. José María Luis Mora, 1999 (Historia económica).

Lugo Pérez, David. Hidalgo. Documentos para la historia de su creación. Pachuca: Instituto Hidalguense de Desarrollo Cultural e Investigaciones Sociales, 1994.

Lyon, George Francis. Residencia en México, 1826, Diario de una gira con estancia en la República de México. México: Fondo de Cultura Económica, 1984.

Meyer, Jean. Problemas campesinos y revueltas agrarias (1821-1910). México, SEPSetentas, 1973.

Moreno Feliu, Paz. ¿El dinero? Barcelona: Anthropos, 1991.

Nickel, Herbert J. Morfología social de la hacienda Mexicana. México: Fondo de Cultura Económica: 1996.

O’Gorman, Edmundo. Historia de las divisiones territoriales de México. México: Porrúa, 2000. 
La formación de un mercado regional en el noreste del valle de México. De minas, ferrocarril...

Ortega Morel, Javier. Minería y ferrocarriles: el caso de Pachuca-Real del Monte, 1870-1906, (tesis de maestría), FFYL/UNAM, 2002 (1 ${ }^{\mathrm{a}}$. edición en Minería y ferrocarriles en la región de Pachuca y Real del Monte durante el Porfiriato, Pachuca: Universidad Autónoma del estado de Hidalgo, 2015).

Ortiz Hernán, Sergio. Caminos y transportes en México. Una aproximación socioeconómica: fines de la Colonia y principios de la vida independientes. México: Secretaría de Comunicaciones y Transportes- Fondo de Cultura Económica, 1994.

Payno, Manuel. Memoria sobre el maguey mexicano y sus diversos productos. México: Imprenta de A. Boix, 1864 (reeditada en Payno, Manuel. Obras completas, vol. XVII. México: Consejo Nacional para la Cultura y las Artes, 2006).

Payno, Manuel. Memoria sobre el ferrocarril de México a Veracruz. México: Imprenta de Nabor Chávez, 1868 (reeditada en Payno, Manuel. Obras completas, vol. XX. México: Consejo Nacional para la Cultura y las Artes, 2007).

Randall, Robert W. Real del Monte: una empresa minera británica en México. México: Fondo de Cultura Económica, 1977.

Rees, Peter. Transportes y comercio entre México y Veracruz, 1519-1910. México: SEP-Setentas, 1976.

Riva Palacio, Vicente y Zárate, Julio. México a través de los siglos (La guerra de independencia-libro segundo), t. VI. México: Cumbre, 1984.

Romero Ibarra, María Eugenia (coord.). Las regiones en la Historia económica mexicana. Siglo XIX. México: Facultad de Economía/UNAM, 1999.

Ruiz de la Barrera, Rocío. La empresa de Minas del Real del Monte (1849-1906) (tesis de doctorado), Centro de Estudios Históricos/El Colegio de México, 1995.

Saavedra Silva, Elvira. Cambios provocados por la actividad minera-metalúrgica en la organización espacial de Pachuca-Real del Monte en el siglo XIX y sus impactos territoriales y socioeconómicos (tesis maestría en Geografía), FFYL/UNAM, 2006.

Semo, Enrique (coord.). Historia económica de México, 13 vols. México: UNAMOcéano, 2004-2006.

Silva Riquer, Jorge (coord.). Los mercados regionales de México en los siglos XVIII y $X I X$. México: Consejo Nacional para la Cultura y las Artes-Instituto de Investigaciones Dr. José María Luis Mora, 2003.

Silva Riquer, Jorge; Grosso, Juan Carlos y Yuste, Carmen (comp.). Circuitos mercantiles y mercados en Latinoamérica, siglos XVIII y XIX. México: UNAMInstituto de Investigaciones Dr. José María Luis Mora, 1995 (Historia económica). 
Silva Riquer, Jorge y López Martínez, Jesús. Mercado interno en México. México: Instituto de Investigaciones Dr. José María Luis Mora -El Colegio de Michoacán- El Colegio de México-UNAM, 1998 (Lecturas de Historia Económica Mexicana).

Ward, Henry George. México en 1827. México: Fondo de Cultura Económica, 1995.

\section{Capítulos de libros}

Arcondo, Aníbal B. "La noción de mercado en economía y su utilización en Historia", en Grosso, Juan Carlos y Silva Riquer, Jorge. Mercados e Historia, México, Instituto de Investigaciones Dr. José María Luis Mora, 1994.

Calderón, Francisco. "El Palacio del rey de Oros", en Historia Moderna de México, vol. II. México: Hermes, 1955.

García de León, Antonio. "Las grandes tendencias de la producción agraria", en Semo, Enrique (coord.). Historia de la cuestión agraria mexicana, vol. 1. México: Siglo XXI editores-Centro de Estudios Históricos del Agrarismo en México, 1998.

Guedea, Virginia. "Ignacio Adalid, un equilibrista novohispano", en Rodríguez, Jaime E. (ed.). Mexico in the Age of Democratic Revolutions, 1750-1850. Boulder \& London: Lynne Rienner Publishers, 1994.

Herrera Canales, Inés. "La racionalidad económica de la empresa minera Real del Monte y Pachuca, 1849-1875", en Anuario II (Organización de la producción y relaciones de trabajo en el siglo XIX en México). Jalapa, Centro de Investigaciones Históricas, Instituto de Investigaciones Humanísticas/Universidad Veracruzana, 1979, pp. 208-223.

Meyer, Rosa María. "Los Béistegui, especuladores y mineros, 1830-1869”, en Cardoso, Ciro (coord.). Formación y desarrollo de la burguesía en México. Siglo $X I X, 2^{a}$. ed. México: Siglo XXI editores, 1981.

Riguzzi, Paolo. "Los caminos del atraso: tecnología, instituciones e inversión en los ferrocarriles mexicanos, 1850-1900", en Kuntz Ficker, Sandra y Riguzzi, Paolo. Ferrocarriles y vida económica en México (1850-1950). Del surgimiento tardío al decaimiento precoz. México: El Colegio Mexiquense-Ferrocarriles Nacionales de México-Universidad Autónoma Metropolitana/Xochimilco, 1996.

Ruiz de la Barrera, Rocío. "La empresa de minas de Real del Monte (1849-1906). Medio siglo de explotación minera: ¿Casualidad o desarrollo estratégico?”, en Marichal, Carlos y Cerutti, Mario (comp.). Historia de las grandes empresas en México, 1850-1930. México: Universidad Autónoma de Nuevo León/Fondo de Cultura Económica, 1997.

Sánchez Santiró, Ernest. "El desempeño de la economía mexicana tras la independencia, 1821-1870: nuevas evidencias e interpretaciones" en Llopis, E. y Marichal C. (coords.). Latinoamérica y España 1800-1850. Un crecimiento 
La formación de un mercado regional en el noreste del valle de México. De minas, ferrocarril...

económico nada excepcional. México: Marcial Pons-Instituto de Investigaciones Dr. José María Luis Mora, 2009.

Sánchez Santiró, Ernest. "El desempeño de la economía mexicana 1820-1860, de la colonia al estado-nación” en Kuntz, Sandra (coord.). Historia económica general de México: de la colonia a nuestros días. México: El Colegio de México-Secretaría de Economía, 2010.

Sempat Assadourian, Carlos. "La organización económica espacial del sistema colonial”, en Silva Riquer, Jorge y López Martínez, Jesús. Mercado interno en México. México: Instituto de Investigaciones Dr. José María Luis Mora-El Colegio de Michoacán -El Colegio de México-UNAM, 1998.

Urías Hermosillo, Margarita. "Manuel Escandón: de las Diligencias al Ferrocarril. 1833-1862", en Cardoso, Ciro (coord.). Formación y desarrollo de la burguesía en México en el siglo XIX, 2a. ed., México: Siglo XXI editores, 1981, pp. 47-55.

\section{Artículos en revistas}

Herrera Canales, Inés. “Empresa minera y región en México. La Compañía de Minas de Real del Monte y Pachuca (1824-1906)", en Siglo XIX. Cuadernos de historia, vol. IV, núm. 8, (julio-diciembre 1979), pp. 103-123.

Ruiz de la Barrera, Rocío. "Acciones y accionistas de una empresa minera del siglo XIX”, Universidad de México, Revista de la UNAM, núm. 544, mayo de 1996, pp. 47-50. 